\title{
STUDIES ON SPASTICITY \\ FROM AN \\ INTERVENTIONAL PERSPECTIVE
}

\section{Per Ertzgaard}

Akademisk avhandling

Om för föreläggande av medicine doktorsexamen offentligen kommer att försvaras i

Belladonna, Campus US (ingång 76), Linköpings universitet

Fredagen den 9 november 2018, kl. 13:00

Fakultetsopponent: professor Jean-Michel Gracies

Médecine Physique, Neurorééducation, Université Paris-Est, Créteil

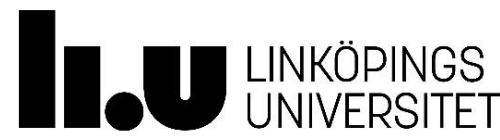

Department of Medical and Health Sciences

Faculty of Health Sciences, Linköping University

SE-581 83 Linköping, Sweden

Linköping 2018 
ISBN 978-91-7685-209-5

ISSN 0345-0082

Printed by LIU-tryck, Linköping, Sweden, 2018

Copyright $($ P Per Ertzgaard 
This thesis focuses on interventional aspects of spasticity, but has a very holistic approach, grounded in the specialty of Rehabilitation medicine. This means capturing the effects of spasticity, on such a complex biological system as the human being, living in a psychosocial context affecting the situation. When evaluating spasticity there are a number of levels of evidence. The first of course, understanding what we mean with spasticity, where there unfortunately is no consensus. The second level is to study if our treatments affect spasticity in a positive direction. The third is to grasp if a decrease in spasticity improve or normalize patient's movement patterns. The fourth level investigates if improvement in movement patterns improve patient's ability to perform activities; and the fifth level, comprising whether this intervention improves life satisfaction. Finally, on a societal level, we wish to investigate whether the improvement in life satisfaction or health related quality of life would motivate society to fund the intervention.

Paper I on Goal Attainment Scaling pointed out necessary aspects to consider when using this instrument. This relates, among other things, to the need of learning ("the art of") goal setting and deciding the purpose of the measurements. Research and clinical use puts different demands on the instrument, for the latter time-efficiency and simplicity to use being most important. For research, it is important to be able to register deterioration, and this can be achieved using the 6-step version.

In paper II, concerning validation of the portable motion system, we showed this system to be valid for short-term measurements and that the use of Exposure Variation Analysis (EVA) seems to be a valuable tool for graphically elucidating different movements. The equipment needs further development in handling long-term measurements (which is effectuated), and norms for normal movements in different activities has to be produced. The discriminative value of EVA needs confirmation in coming studies. For the future, there is the intriguing possibility of long-term measurements in patients' every-day life, thereby getting objective measures on how our patients use their abilities, thus capturing the difference between what you can do and what you actually do.

The results from paper III demonstrated a large inequality in Sweden regarding the accessibility of BoNT-A treatment for spasticity. We could also show that treatment with BoNT-A is sound from a health-economic perspective, accounting for the uncertainty of data via the sensitivity analysis. For the future, we need to explore if this inequality also exists for other modes of spasticity treatments, e.g. multidisciplinary spasticity treatment and ITB pumps, and in other countries.

In paper IV evaluating multifocal TES, the results could not confirm efficacy with the treatment according to the protocol of the manufacturer. The results have to be interpreted with care, as low compliance and frequent adverse events made deduction difficult. Individual patient anecdotes, from the study, implicate that there is an effect 
not captured in the RCT study. Further studies are needed in a number of areas, e.g. what is the optimal stimulation frequency, what patients can gain from the treatment and how should adjunct treatment be organized.

In this thesis, I have had the privilege to explore different methods of evaluating spasticity interventions from a multimodal perspective as a starting point in an effort to understand more of this intriguing phenomenon. Some of the research questions above are already in the "pipeline" for coming studies; others are to be planned by our research group and others. 


\section{CONTENTS}

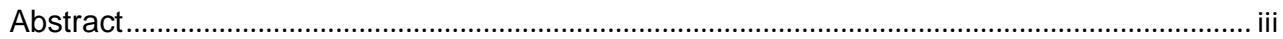

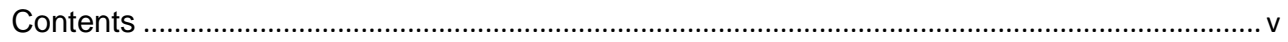

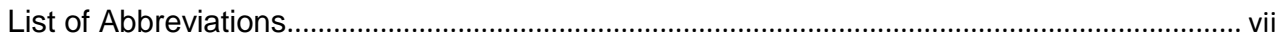

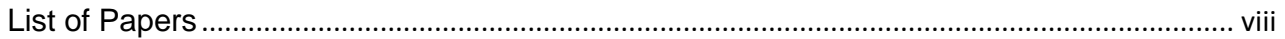

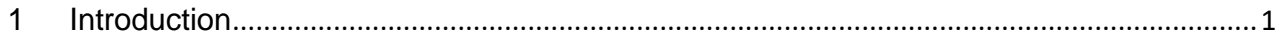

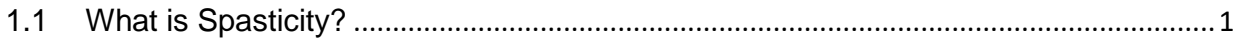

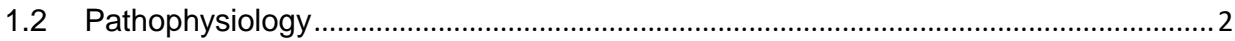

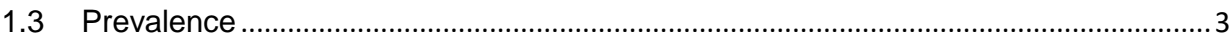

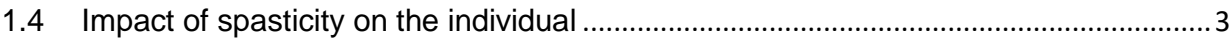

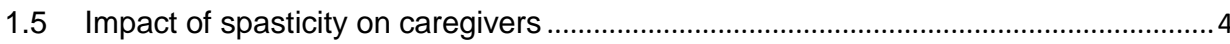

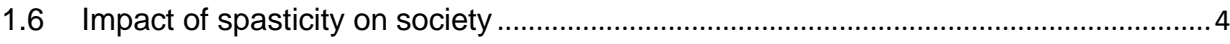

1.7 The role of ICF in spasticity management and research ............................................. 4

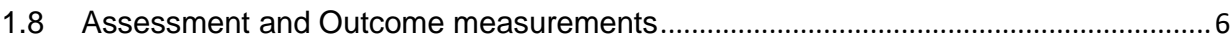

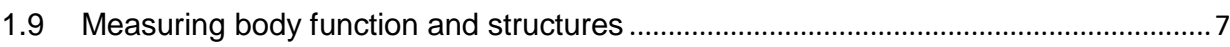

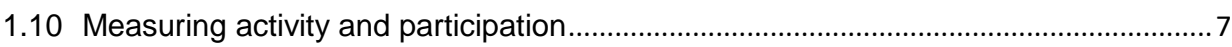

1.11 Health Related Quality of Life (HRQoL) instruments .................................................. 8

1.12 Canadian Occupational performance measure (COPM) ............................................... 9

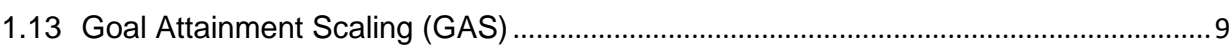

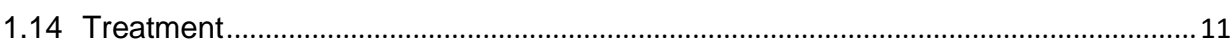

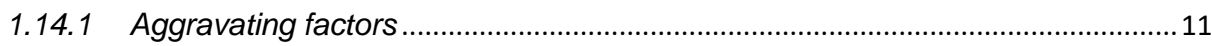

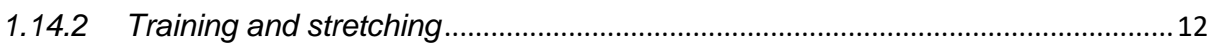

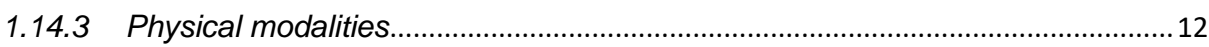

1.14.4 Pharmacological treatment for regional or generalized spasticity ........................13

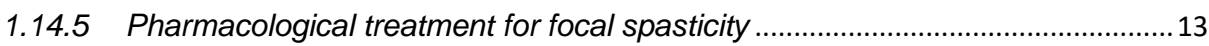

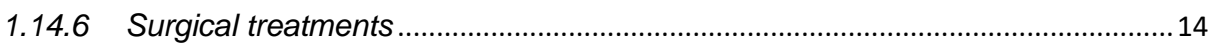

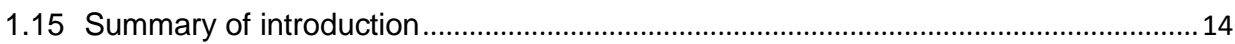

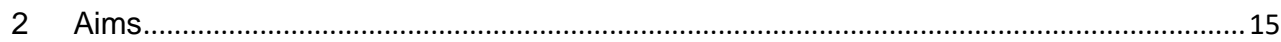

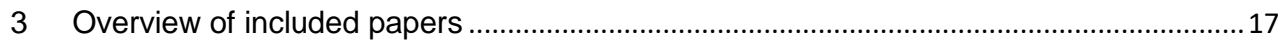

4 Goal Attainment in evaluation of spasticity (Paper I) .........................................................19

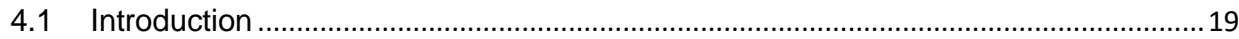

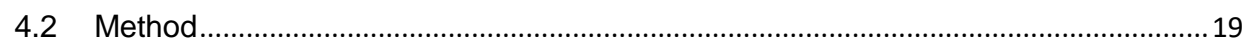

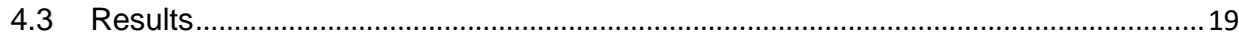

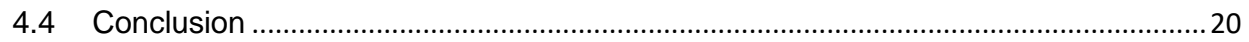


$5 \quad$ Validation of a system for portable movement analysis (Paper II) ....................................21

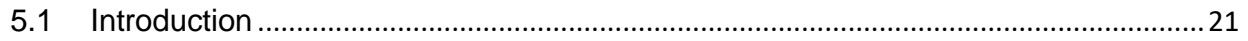

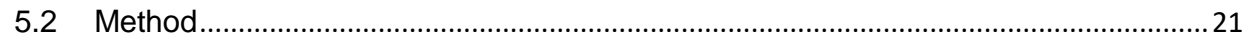

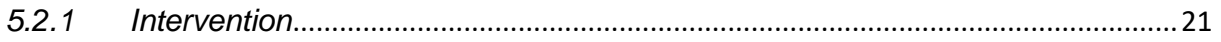

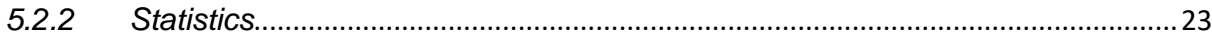

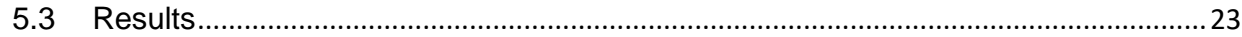

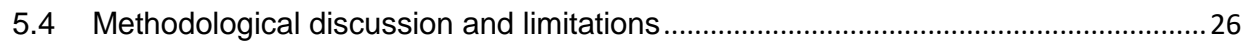

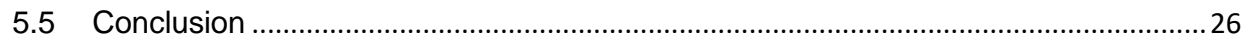

6 Inequality in spasticity care, an health-economy study (Paper III) ....................................2

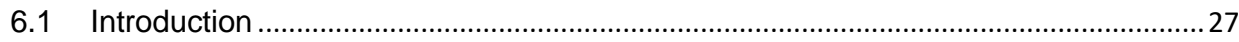

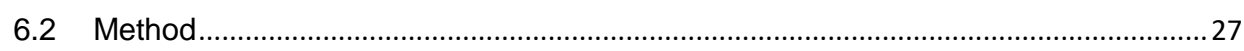

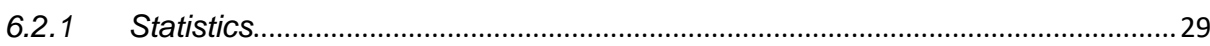

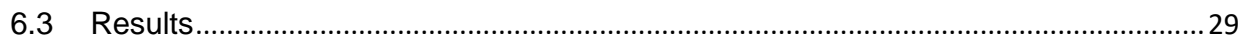

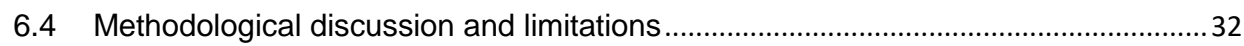

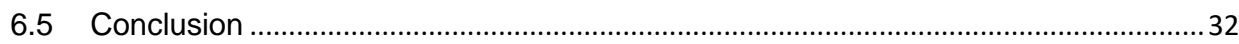

7 Evaluation of a comprehensive system for TES treatment of spasticity (Paper IV) .........33

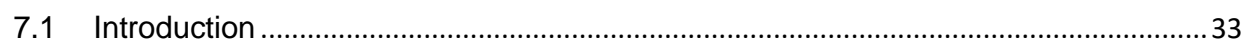

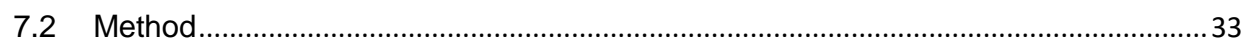

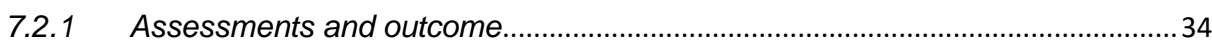

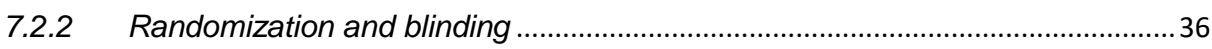

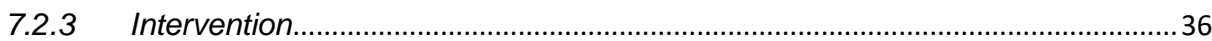

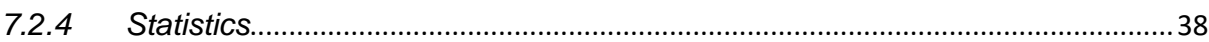

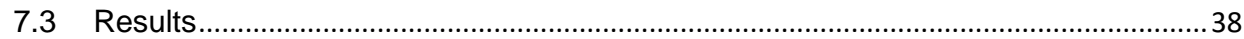

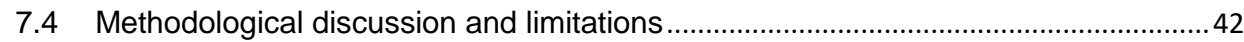

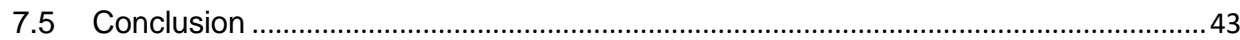

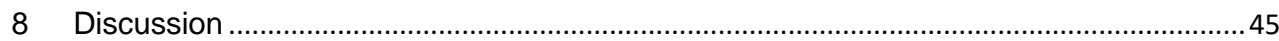

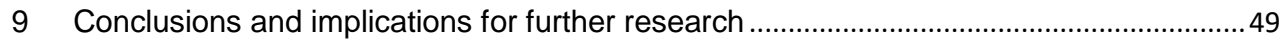

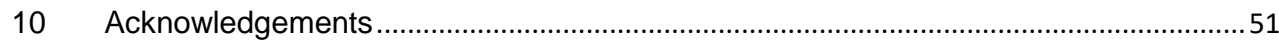

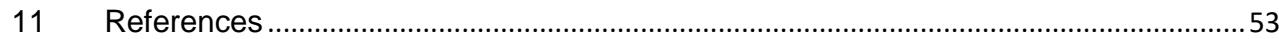

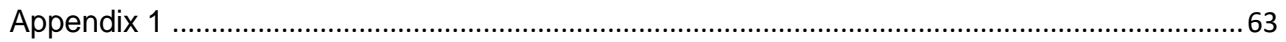




\section{LIST OF ABBREVIATIONS}

\begin{tabular}{|c|c|}
\hline $\mathrm{ABI}$ & Acquired Brain Injury \\
\hline ADL & Activities of Daily Life \\
\hline AT & Assistive Technology \\
\hline BoNT-A & Botulinum toxin type $\mathrm{A}$ \\
\hline CGT & Comfortable Gait Test \\
\hline CIMT & Constraint Induced Movement Therapy \\
\hline CNS & Central Nervous System \\
\hline COPM & Canadian Occupational Performance Measure \\
\hline $\mathrm{CP}$ & Cerebral Palsy \\
\hline DRST & Dorsal reticulospinal tract \\
\hline EVA & Exposure Variation Analysis \\
\hline FES & Functional Electrical Stimulation \\
\hline FGT & Fast Gait Test \\
\hline GAS & Goal Attainment Scaling \\
\hline GMFCS & Gross Motor Function Classification System \\
\hline HRQoL & Health Related Quality of Life \\
\hline ICD & International Classification of Diseases \\
\hline $\mathrm{ICF}$ & International Classification of functioning, disability and health \\
\hline ICIDH & International Classification of Impairments, Disabilities and Handicaps \\
\hline ITB & Intrathecal Baclofen \\
\hline ITT & Intention To Treat \\
\hline MRST & Medial reticulospinal tract \\
\hline MS & Multiple Sclerosis \\
\hline NIHSS & National Institutes of Health Stroke Scale \\
\hline NMES & Neuromuscular Electrical Stimulation \\
\hline NRS & Numerical Rating Scale \\
\hline PP & Per Protocol \\
\hline PRO & Patient Reported Outcome \\
\hline PSS & Post-Stroke Spasticity \\
\hline QALY & Quality Adjusted Life Years \\
\hline $\mathrm{RCT}$ & Randomized Controlled Trial \\
\hline SCI & Spinal Cord Injury \\
\hline SDR & Selective Dorsal Rhizotomy \\
\hline TBI & Traumatic Brain Injury \\
\hline TENS & Transcutaneous Electrical Nerve Stimulation \\
\hline TES & Therapeutic Electric Stimulation \\
\hline TUG & Timed Up and Go \\
\hline VST & Vestibulospinal tract \\
\hline
\end{tabular}




\section{LIST OF PAPERS}

Paper I: Ertzgaard, P., Ward, A. B., Wissel, J., \& Borg, J. (2011). Practical considerations for goal attainment scaling during rehabilitation following acquired brain injury. J Rehabil Med, 43(1), 8-14.

Paper II: Ertzgaard, P., Ohberg, F., Gerdle, B., \& Grip, H. (2016). A new way of assessing arm function in activity using kinematic Exposure Variation Analysis and portable inertial sensors--A validity study. Man Ther, 21, 241-249.

Paper III: Ertzgaard, P., Anhammer, M., \& Forsmark, A. (2017). Regional disparities in botulinum toxin A (BoNT-A) therapy for spasticity in Sweden: budgetary consequences of closing the estimated treatment gap. Acta Neurol Scand, 135(3), 366372 .

Paper IV: Ertzgaard, P., Alwin, J., Sorbo, A., Lindgren, M., \& Sandsjo, L. (2018). Evaluation of a self-administered transcutaneous electrical stimulation concept for the treatment of spasticity: a randomised placebo-controlled trial. Eur J Phys Rehabil Med. 54(4), 507-517. 


\section{INTRODUCTION}

\subsection{What is Spasticity?}

The view on what should be included in the term "spasticity" has changed over the years, and is far from clear-cut in its demarcation vis-a-vis other movement disorders, not least the phenomena of "spastic dystonia" [1] and "spastic rigidity" [2]. So, when discussing the concept of "spasticity", we have to start with at least a consensus definition of the concept.

Since 1980, and still today, the definition by Lance is the most commonly referred: "A velocity-dependent increase in tonic stretch reflexes (muscle tone) with exaggerated tendon jerks, resulting from hyperexcitability of the stretch reflex, as one component of the upper motor neuron syndrome" [3]. This definition, however, is criticized for only considering part of the positive symptoms seen in an upper motor neuron syndrome. In 2005, Pandyan et al published a wider definition : "Disordered sensorimotor control, resulting from an upper motor neuron lesion, presenting as intermittent or sustained involuntary activation of muscles" [4], thus including all symptoms related to lack of central inhibition of spinal reflexes. This definition is increasingly used, and is the one related throughout this thesis, with certain modifications, see figure 1. Still, many authors prefer using the term "spasticity" specifically for the increase in spinal reflexes [1]. This notwithstanding, for both clinical and research purposes, the different patterns/subtypes of spasticity have to be specified, as different treatment modalities may, and will, differ in their effect on different spastic phenomena [2, 5].

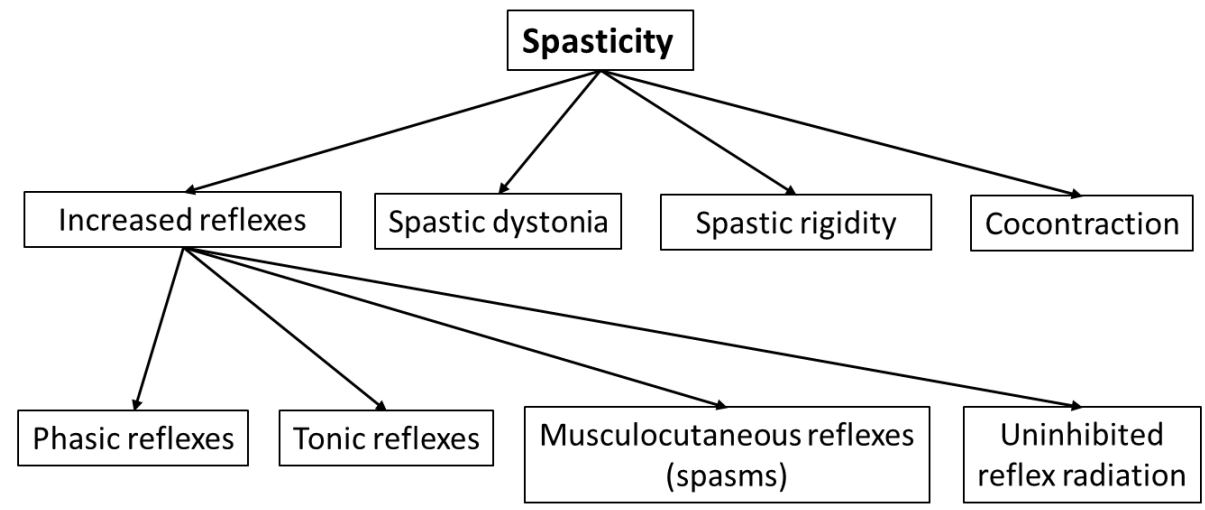

Figure 1: Different phenomena included in the concept of spasticity developed from Pandyan $2005[1,2,4]$.

Spasticity may have both beneficial and detrimental effects, e.g. it may act as support in transfers or, conversely, restrict transfers due to stiffness. As a matter of course, for therapeutic interventions, only patients with mainly negative effects should be candidates. Such negative predominance, if clinically significant, may be denoted 
"disabling spasticity", thus being defined: "Spasticity which is perceived by the individual and/or the caregiver as hindering body function, activities and/or participation" [6].

\subsection{Pathophysiology}

Spasticity is one of several results of an injury to the central nervous system (CNS), often called an upper motor neuron syndrome, also including paresis, and affected by sensory deficits and secondary effects on muscles. The latter is denoted myogenic factors. In clinical work, it is important, but often difficult, to differentiate paresis and myogenic factors from spasticity.

There is a positive correlation between the degree of loss of sensation and the severity of spasticity [7], as well as between the degree of paresis and the severity of spasticity [8]. Thus, severity of sensorimotor loss is a negative prognostic factor for spasticity development in the early stage of a CNS injury. In sudden lesions to the CNS, there is a delay of days to weeks from injury until spasticity evolves, indicating that CNS plasticity plays a significant role in the development [8-12].

I will now start describing the effects on muscles, in spite of these not being part of spasticity as defined. Thereafter, I discuss mechanisms at the spinal cord level, and ultimately those involving the brain.

In spastic paretic muscles, there is often a shortening and stiffness hindering the range of movement. This may be caused by a loss of sarcomeres and increases in the proportion of intramuscular connective tissue and fat deposits [13, 14]. This stiffness is often difficult to discriminate from the spastic component proper [15]. Later in the process, stiffness also often relates to extra-muscular connective tissue and joints [16]. At the spinal cord level, there is an increased activity in the $\alpha$-motoneurons. There are a number of possible reasons for this, where a decreased reciprocal inhibition of the stretch reflex, both type Ia and Ib, is best corroborated. The fusimotor fiber $(\gamma-$ motoneuron) hypothesis, nowadays not considered a significant contributing factor for human spasticity. Other proposed factors at the spinal cord level are denervation supersensitivity and lowered post-activation depression, both putatively contributing to spasticity $[13,17]$.

Contrary to common opinion, an isolated lesion of the corticospinal tract does not seem to cause spasticity [18]. Rather, there are three other main tracts originating in the brain being involved in spasticity: the dorsal reticulospinal tract (DRST), the medial reticulospinal tract (MRST) and the vestibulospinal tract (VST). Of these, the DRST is inhibitory, while the MRST and the VST are excitatory on the spinal stretch reflex. The DRST and the VST are modulated from higher cortical areas. VST is considered mainly involved in decerebrate rigidity $[15,19]$.

In summary, spasticity is an expression of an over-activity at the level of the $\alpha$ motoneuron, where spinal mechanisms interact with an imbalanced descending 
regulation. Depending on the lesion location, and tracts involved, we will see different spasticity patterns. As an example of this, we can note the difference in spasticity in spinal cord versus brain lesions, where increased reflexes dominate in spinal cord injuries whereas brain injuries display more of other phenomena, e.g. spastic dystonia (Figure 1).

\subsection{Prevalence}

There is a scarcity of solid epidemiological data on the prevalence of spasticity. More than anything, the numbers differ hugely. For post-stroke spasticity (PSS), the prevalence varies between $7.6 \%$ to closer than half the population 12 months poststroke [9, 20-22]. For spinal cord injury (SCI) and multiple sclerosis (MS), the prevalence of spasticity seems to be around $2 / 3$ of the population [23-25] and for cerebral palsy (CP) more than $80 \%$ have a spastic type [26]. For traumatic brain injury (TBI), data is scarcer, though it seems that around 1/3 develop spasticity after moderate to severe TBI. A recent publication by our group has attempted to approximate the prevalence of disabling spasticity in Sweden for the main etiologies, i.e. PSS, SCI, MS, $\mathrm{CP}$ and TBI [27]. Based on these data, the prevalence of spasticity in Sweden would approximate 56000 individuals, and disabling spasticity 21000 individuals.

\subsection{IMPACT OF SPASTICITY ON THE INDIVIDUAL}

CNS disorders, where spasticity is a frequent component, also comprise a diverse array of other debilitating symptoms, e.g. paresis, sensory loss, autonomic dysfunction of urinary bladder, bowel and sexual function, decreased respiratory and circulatory capacity, and in brain injuries, cognitive and behavioral impairment. These problems have a major negative impact on the quality of life of afflicted individuals. Measurements of Health Related Quality of Life (HRQoL) in CNS disorders, typically and unsurprisingly, show a decrease compared to the normal population (SCI [28, 29], MS [30, 31], Stroke [32, 33], TBI [34]).

In the presence of this array of symptoms, it is clear that measuring the contribution by spasticity becomes complex, not least as the severity of spasticity covariates with severity of other problems due to a CNS lesion [35]. Thus, it is difficult to isolate the disability related to spasticity proper from the disabling effects of other symptoms. In addition, and as has already been mentioned, spasticity can be beneficial in its moderate form, but often becomes debilitating and quality of life hampering when becoming severe. For most diagnoses there is a correlation between increased spasticity and decreased quality of life [36-39] and more clearly so when severity of spasticity is also considered [40]. 


\subsection{IMPACT OF SPASTICITY ON CAREGIVERS}

Many CNS disorders put a strain on caregivers, often relatives, affecting their everyday lives in a negative way. An increased need for support in daily activities, requires greater hours of caregiver assistance [41]. The increased burden on caregivers lowers their HRQoL [42] and decreases their mental and physical health [43] with increased anxiety and depression [44]. The importance of spasticity on caregiver burden is difficult to study in isolation from the condition. However, treatments reducing spasticity also decreases caregiver burden and caregiver depression in PSS [43, 45]. It also reduces caregiver burden for patients in long-term institutions [46].

\subsection{IMPACT OF SPASTICITY ON SOCIETY}

Apart from the suffering of individuals, spasticity exerts a major economic impact on society, by increasing costs of care and treatment [35, 47]. This relates to both societal and health care costs [47], as well as to costs related to caregiver burden [6, 48]. Although the costs for treatment are considerable, treatment for spasticity nevertheless appears to be cost-effective [49-51]. Further elaboration on this aspect, by our group, is presented in paper III [27].

\subsection{THE ROLE OF ICF IN SPASTICITY MANAGEMENT AND RESEARCH}

Over time, the insight has emerged that it is not enough to measure outcome as it only pertains to body functions and structures. Our patients exist, as all human beings, within a psychological and sociological context, affecting the results of our treatments. Ultimately, it is the effect on the patients' functioning in everyday life that matters and thus has to be evaluated. In this process, the development of the International Classification of Functioning, Disability, and Health (ICF) has been crucial in representing such a more realistic framework for human functioning.

When ICF was first published in 2001 [52], it substituted the International Classification of Impairments, Disabilities and Handicaps (ICIDH) from 1980. Before the development of ICIDH, there was a discussion on the relation between body defect/impairment and disability. This evolution, towards the development of ICF, has been described, among others, by Thyberg et al [53]. Conceptually, ICF describes the effect of a health condition on body function and structures, on activities and participation, where the demarcation between activities and participation depends on whether or not the activity is performed within a social/environmental context. The concept also considers the influence from environmental and personal factors (figure 2). In addition to the conceptual framework, ICF includes a coded classification, in analogy with the International Classification of Diseases (ICD) [54]. In the latest ICD generation (ICD-11), part of the ICF taxonomy has been included. 


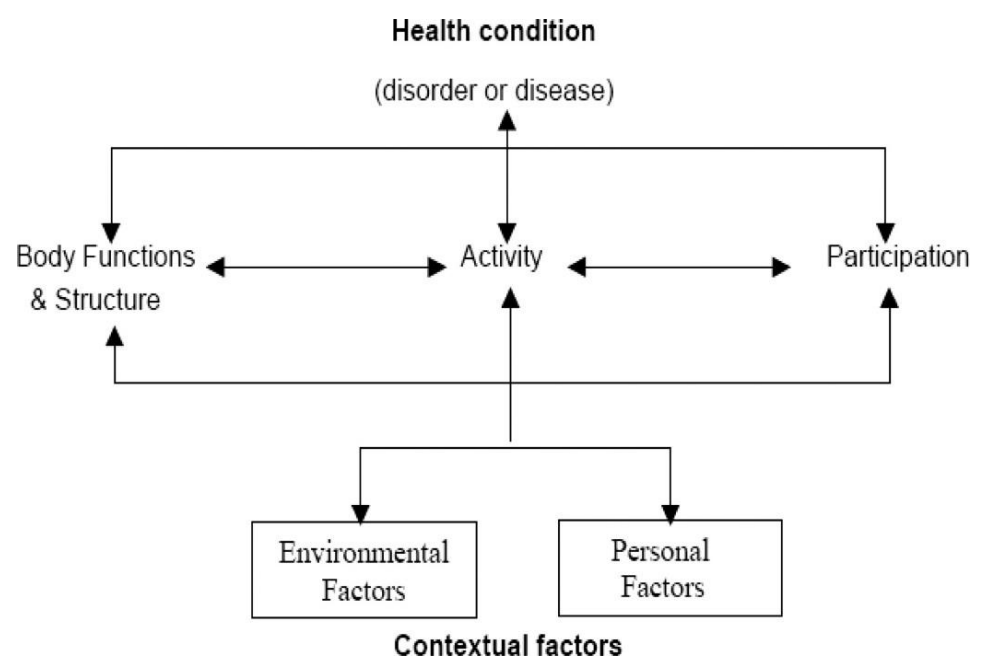

Figure 2: Graphical presentation of the ICF taxonomy and relations between concepts.

Within the rehabilitation community, the ICF taxonomy now is generally accepted. There are a number of different subsets, developed to facilitate the use of ICF (relationship illustrated in figure 3), as well as different ways of implementing the ICF taxonomy:

1. The ICF Generic set, consisting of 7 ICF categories, is intended to address the comparability of data across studies and countries [55].

2. The more extended ICF Rehabilitation set, consists of 30 ICF categories, and is intended as a minimal standard for reporting and assessing functioning and disability in clinical populations, along the continuum of care [56].

3. A number of Core sets for different health conditions, e.g. SCI, where the most relevant codes for the specific disorder are presented as a short list, to capture the problems of the patients.

4. The use of ICF, and its core sets, as a checklist against which relevant aspects are included in clinical follow-up and in research. This can be done by mapping different/plausible instruments towards the relevant ICF categories [57, 58], thereby optimizing the choice of and the number of instruments to be used.

5. In development of new instruments [59]. 


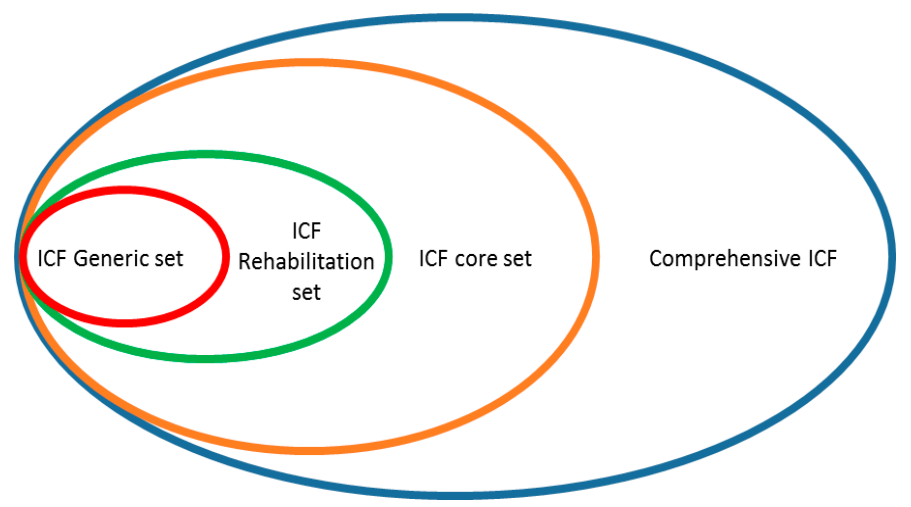

Figure 3: Relations between different subsets of ICF.

\subsection{ASSESSMENT AND OUTCOME MEASUREMENTS}

The main purpose of, on the one hand, an assessment and, on the other hand, an outcome measurement, differ somewhat. An assessment aims to understand the condition (most often on body function and structure) to enable us to tailor our treatment efforts. The purpose of an outcome measurement, by contrast, is to evaluate if our treatment has had the intended effect and thereby decreased the suffering of the patient. To know if our intervention was successful, we need evaluations of goal attainment or see an increase in HRQoL measures. Figure 4 illustrates the role of the different ICF concepts in evaluation from a clinical standpoint. Correspondingly, choice of instruments in research obviously depend on which ICF concepts that are under study. These different levels are elaborated in chapter 8 , Discussion.

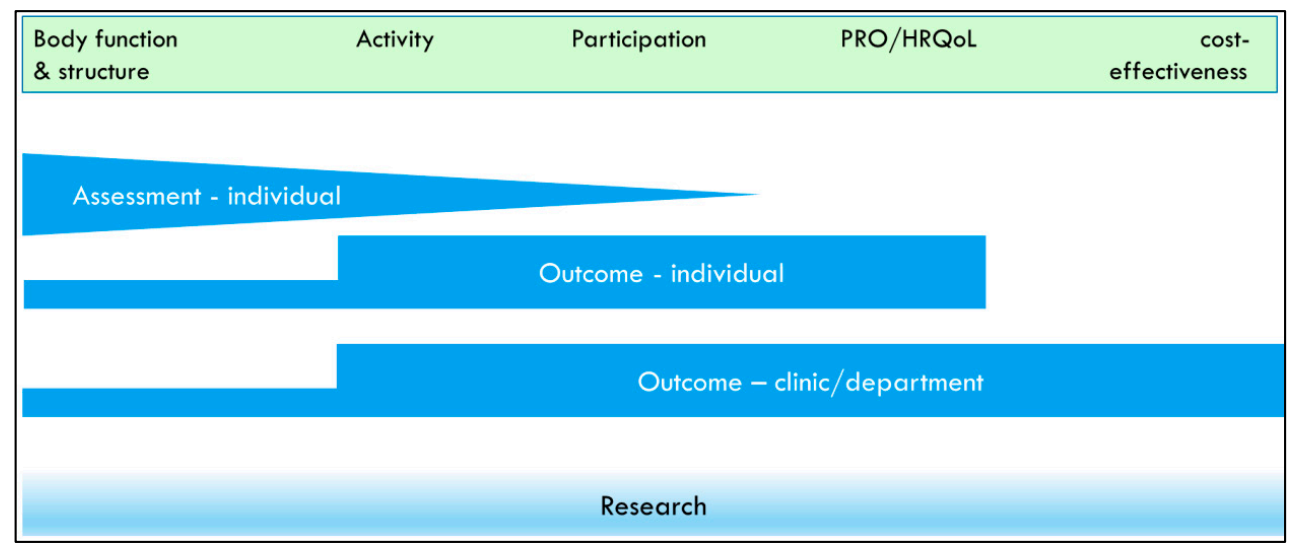

Figure 4: The relation between evaluation and different categories of measurement. 
There are a large number of instruments measuring various aspects of functioning, and it is beyond the scope of this thesis to describe all these, though some of the most relevant will be described below. The choice of instrument depends on psychometric properties like validity, reliability and responsiveness; on the population intended for intervention (e.g. to avoid floor and ceiling effects), as well as on the expected effect of the intervention. Time efficiency is also a factor to be considered, as measuring must be practicable both for the patient and the team. There are a few recent publications reviewing different instruments used in evaluation of spasticity [60, 61]. In 2015, the Ability Network did a thorough inventory on the instruments being used in spasticity research, where the instruments related to SCI has been published [60]. In appendix 1, all instruments for all diagnoses are presented for the first time. For further information, websites like the Rehabilitation Measures Database is of use:

https://www.sralab.org/rehabilitation-measures.

\subsection{MEASURING BODY FUNCTION AND STRUCTURES}

There are two types of clinical instruments relating to body function. The first type is those measuring spasticity per se, and its different components (see figure 1). Examples of these are Ashworth/Modified Ashworth Scale and Modified Tardieu Scale, Clonus Score and Penn Spasm Frequency Scale. There are also composite measures, including several of the spastic phenomena, e.g. Composite Spasticity Scale and Spinal Cord Assessment Tool Spastic Reflexes (SCATS).

The other type of measures pertaining to body function are measurements on related phenomena, e.g. range of motion, motor function and pain that correlate with spasticity. Further information can be found in appendix 1 (table 1). In the paper by Nene et al [60] and at https://www.sralab.org/rehabilitation-measures, some of these instruments are evaluated regarding their usefulness and psychometric properties.

\subsection{MEASURING ACTIVITY AND PARTICIPATION}

Instruments relating to activity and participation are mainly developed for dexterity and gait evaluation. Some of these are composite measures, e.g. the Lindmark Motor Assessment Scale and the Gross Motor Function Measure (GMFM). Another category comprises instruments used for activities of daily life (ADL), e.g. Barthel Index and Functional Independence Measure (FIM). The instruments are sometimes adapted to a defined diagnosis, e.g. SCIM as an adaption of FIM. Appendix 1 (table 2) gives information regarding which instruments have been used for assessments in different health conditions.

Clinical instruments cannot capture the qualitative aspects of movements, i.e. they do capture functional ability but remains silent as to how this ability is achieved. For this, we need a precise movement analysis as in a movement laboratory. Unfortunately, the 
use of these is both expensive and time-consuming, as well as not being available in most places. Portable inertial systems for movement analysis are under development. These will provide complementary possibilities for qualitative assessment.

\subsection{HeALTH RELATED QUALITY OF LIFE (HRQOL) INSTRUMENTS}

Patient Reported Outcomes (PRO) comprise a group of instruments used to obtain information on subjective experiences, as pain, quality of life, self-appreciated functional status, satisfaction with care and/or compliance with medication-essentially anything that patients may know first-hand and that is appropriate for them to report [62]. Examples of PROs commonly used are HRQoL instruments, Canadian Occupational Performance Measure (COPM) and Goal Attainment Scaling (GAS). HRQoL instruments generally have good psychometric properties and focus on factors relevant from a health perspective. There are four main types of HRQoL instruments, described below:

1. Generic instruments (e.g. SF-36, EQ-5D and WHOQOL-BREF) designed to be used with any health condition or population sample. One major purpose is to enable comparison between different diagnoses.

2. Disease-specific instruments (e.g. for SCI such as, SCI QL-23), for assessment of symptoms and limitations related to a specific disease.

3. Condition-specific instruments (e.g. for spasticity SCI-SET or PRISM), assessing the subjective experience relating to a specific phenomenon such as spasticity.

4. Utility measures for health economic evaluations, mainly EQ-5D, SF-6D and HUI. These are constructed to calculate so-called quality-adjusted life-years (QALY) for use in different economic studies on health care effectiveness. One QALY is representing one year in perfect health and has the measure 1.0 in a scale from 0-1. Each health condition can reduce this figure, both by reducing the quality of life each year, e.g. 0.65 instead of 1.0, and/or by shortening the life-span, thus reducing the number of years lived with the calculated QALY. From this, the cost of a health intervention can be compared to the health gains as cost/QALY. This can then be used as an indicator on whether or not the public health-care system should fund an intervention.

The choice of instruments depends on the research question or clinical question. Apart from instruments being valid and reliable, they should also be reasonably sensitive for change. The condition-specific instruments are more sensitive, but with the disadvantage that results are not comparable across diagnoses. 


\subsection{CanAdian Occupational PERFormance meAsure (COPM)}

COPM, introduced in 1991, identifies problems within the areas of self-care, productivity and leisure, through semi-structured interview. The patients rate the identified problems according to subjective importance from 1-10. The five main problems to focus on are thereafter decided, and each of these is rated from 1 to 10 , according to how the patient rates his/her ability to perform and his/her satisfaction with that performance. Repeating the ratings after an intervention shows the success, or otherwise, of the intervention from the patients' perspective. Higher ratings indicate greater importance, performance and satisfaction. COPM has good validity, high reliability and excellent responsiveness [63]. A change of two score steps or more (out of 10), is considered clinically significant.

\subsection{Goal Attainment Scaling (GAS)}

The concept of Goal Attainment Scaling (GAS) was first published in 1968 [64]. It is considered suitable for individual and group outcome analysis, when evaluating diverse and individualized treatments [65]. The concept has subsequently been implemented in a large number of contexts, and for various health conditions [65-74].

The key issue in GAS is to identify patient-relevant treatment goals. These are often defined in dialogue between the therapist/team and the patient/client [75].Thereafter, these goals are typically "scaled" from -2 to +2 , with 0 being the primary goal of intervention. Thus, the instrument acknowledges that goal achievement, not only may mean actually precisely fulfilling the set goal, but also may mean an achievement towards the goal, and sometimes even exceeding expectations [76]. There are various versions of GAS, and various ways of analyzing the GAS scores. These options are discussed in paper I [77].

There are some clear advantages with GAS, it being sensitive to change [78], patientrelevant and well suited to capture issues not focused in more standardized instruments $[69,79]$. It enhances empowerment and motivation, and allows comparisons between patients with varying levels of functioning. The process of goal setting as such improves collaboration between client and therapist by enhancing the clients understanding of what is needed to reach the goal $[74,79,80]$. It encourages the team to achieve a coordinated multidisciplinary effort, with improved information sharing [81]. GAS may include any level or domain of the ICF [82]. In order to capitalize on these strengths, it is crucial that the process of goal setting takes into account personal needs and preferences of the patient [83].

Kiresuk et al (1994), described typical problems in goal setting [75], see table 1. The process is time consuming, particularly for those inexperienced with GAS [74, 79, 84]. Problems appear when patients suffer impaired insight, emotional and/or communicative dysfunction, when comorbidity occurs between measurements, and/or when goals change along the rehabilitative process [83]. 
Table 1: Problems in GAS according to Kiresuk.

\begin{tabular}{ll}
\hline Problem & Example \\
\hline Clerical problems & Missing essential words of scale levels, time frames \\
Jargon or technical language & Increasing the risk for misunderstanding \\
Vagueness & Lack of specificity, risk for misunderstanding \\
Overlapping levels & Scoring can be within two levels simultaneously \\
Gaps between levels & Scoring can land between levels \\
Multidimensional scales & Two or more dimensions are included on a single scale \\
Blank levels & Confusing \\
\hline
\end{tabular}

The psychometric properties of GAS are generally good to excellent, including responsiveness [66, 71, 78, 85, 86], validity and reliability [80, 85-94], although it is highly reliant on the clinical skills of goal setters [78] and upon the soundness of criteria used to define individual GAS levels $[68,79,95]$. There is a risk for bias, depending on whether goals are too easy or too difficult to achieve [80]. Goals too easy to attain may inflate the treatment effect. In conclusion, there is sufficient evidence to support GAS as an outcome measure in an adult rehabilitation setting [96], although most authors recommend GAS as a complement to more standardized instruments and not as a replacement [97]. 


\subsection{TREATMENT}

Before contemplating spasticity treatment, the first step is to consider the impact of spasticity as such on the problem presented. If spasticity indeed is a main cause of disability, it should then be characterized as being focal, multifocal, regional or generalized. Treatment strategies differ with such different spasticity patterns, as illustrated in figure 5 .

In all spasticity evaluation and treatment, a multidisciplinary team approach is a necessity to capture the complexity of the condition and to be able to offer an optimal treatment regime.

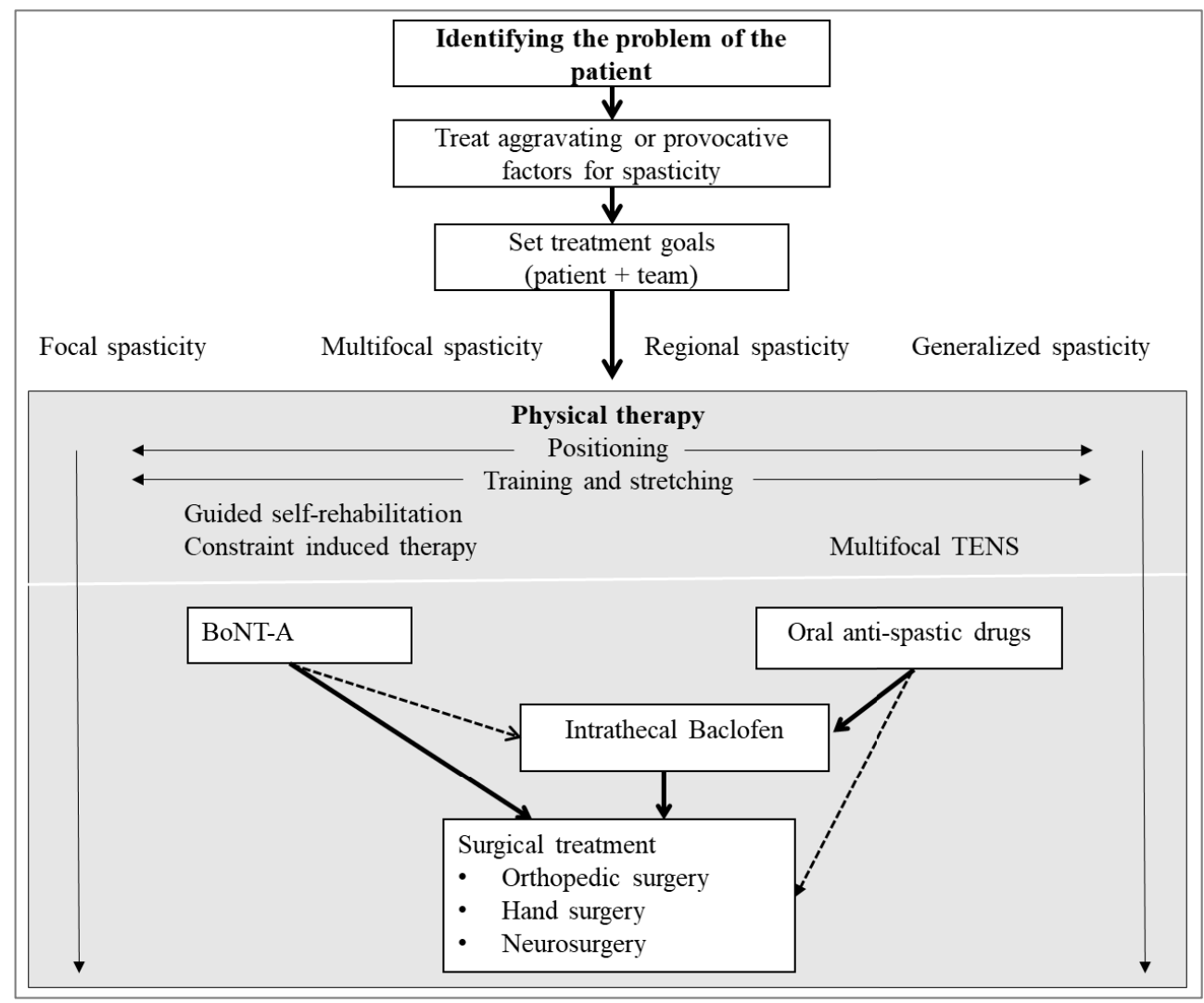

Figure 5: Treatment algorithm for spasticity.

\subsubsection{Aggravating factors}

Spasticity is typically a dynamic phenomenon, influenced by numerous either aggravating or ameliorating factors. The most straightforward way to characterize aggravating factors is to note that any nociceptive or arousing stimulus may aggravate spasticity. For patients with spasticity due to brain injuries, like stroke, TBI or CP, it 
can also be loud noises, uncomfortable seating, anxiety, skin ulcers et cetera [98]. For patients with spinal cord lesions, stimuli coming from below the injury level may aggravate the spasticity [99]. Examples of this include obstipation, urinary tract infection, skin ulcer, fracture, but may be as subtle as a stroking of the leg [98]. If patients are complaining of increased spasticity, the first measure is to rule out aggravating stimuli before contemplating any other treatment.

\subsubsection{Training and stretching}

It has to be clearly underscored that the foundation of all spasticity management always should be physical therapy and training, where spasticity treatment fuses with the other training goals of the patient. A number of physical treatment modalities are in common use. Scientific evidence is sometimes limited [100, 101], though fairly good evidence applies to so-called Constraint Induced Movement Therapy (CIMT) [102].

There is still limited evidence for standard care with stretching of spastic muscles [103, 104]. However, some support is now emerging that so-called self-guided rehabilitation, where the patient performs stretching exercises and motor training daily, might improve range of motion and walking speed $[105,106]$. However, the method is still not implemented in the general rehabilitation community [107].

Often it is difficult to deliver hands-on stretching over a sufficiently long period. In those cases, splinting or casting is an alternative [108]. Also, standing or a tilt-table might be useful for the lower limbs [109]. In the early stage, it may be important to have a strategy for systematic positioning to decrease the risk for muscle shortening. For all of these strategies, evidence is very scarce [110].

\subsubsection{Physical modalities}

Therapeutic electrical stimulation ( TES) for the reduction of spasticity, has been used for decades [111]. TES may be considered as an umbrella term including all modes of electrical stimulation used therapeutically, including transcutaneous electrical stimulation (TENS), and Neuromuscular Electrical Stimulation (NMES), that includes functional electrical stimulation (FES) $[112,113]$. TENS is used either for stimulating muscle contraction with low-frequency stimulation, or for sensory stimulation with high-frequency stimulation. NMES and FES stimulates muscle contraction to achieve a function, i.e. dorsiflexion of the foot during gait. The spasticity-ameliorating mechanism is a reduction of alpha motoneuron excitability [112]. Changes in corticomotoneuronal excitability have been suggested [114] and might contribute. A recent review concludes that there is good evidence for short-term effects with TES as adjunct therapy for spasticity [115]. Another physical modality, vibration therapy, shows more conflicting results as regards efficacy [116-118]. There are a number of other treatment modalities for spasticity reduction, however, much more research are needed before these can be implemented in clinical practice [119]. 


\subsubsection{Pharmacological treatment for regional or generalized spasticity}

Treatment with oral drugs, in Sweden mainly baclofen, is the commonest pharmacological anti-spastic treatment. To a lesser extent, Sativex, is used for spasticity in MS. Other oral drugs, used on licence or off-label, are tizanidine, dantrolene, bensodiazepines, gabapentin and pregabalin. There are often significant cognitive side effects [120], especially in conditions with already compromised cognition. In addition, the therapeutic effect is often modest $[121,122]$. In spite of this, oral drug treatment is still used as the first pharmacological step in regional or generalized spasticity.

If oral drugs are insufficient or carry too much side-effects, then intrathecal baclofen (ITB) is an option, with very good evidence on spasticity reduction [123]. This is probably the most efficient therapy, but it is complex to administer and expensive, therefore mainly being an option for those with disabling spasticity where other treatment options failed ([124]. ITB treatment is also associated with frequent complications, as infections and catheter dysfunctions, and therefore needs thorough and continuous follow-up [125-127].

\subsubsection{Pharmacological treatment for focal spasticity}

For focal spasticity, focal treatment is preferred, mainly with botulinum toxin A (BoNTA) [128]. Historically phenol or alcohol injections were quite common $[129,130]$, but with the development of BoNT-A, this is more rarely used. BoNT-A is used for a vast array of indications in addition to spasticity, including a number of off-label indications. Examples of approved indications are hyperhidrosis, hypersalivation, blepharospasm, cervical dystonia and overactive urinary bladder. The off-label indications are numerous, but one example is different types of pain. One reason BoNT-A is so effective in such different conditions is its action on a common mechanism for transmitter release in the neural synapses, independent of the transmitter-substance being released [131].

Nowadays, BoNT-A treatment for spasticity is "treatment of choice" in disabling PSS [132]. The recommendation is always to treat in conjunction with physical therapy and always use guided injection with electromyography, electrical stimulation and/or ultrasound.

The scientific evidence in favour of treatment with botulinum toxin is very good, with no other spasticity drug having been so extensively studied. BoNT-A treatment is safe and have few serious adverse events $[133,134]$. The effect on reduction of muscle tone is conclusive. Evidence for improvements in activity, participation and HRQoL is emerging, though still not conclusive $[133,135]$. It seems that a gain in activity and participation is an adaptive process, needing repeated treatments in conjunction with training [136]. Still, there are concerns about the optimal adjunct treatment to improve functioning, optimal individual dosages [137] and timing of treatment [138]. 


\subsubsection{Surgical treatments}

Surgical treatment is common in the treatment of spasticity. It is targeted at either the nervous system (CNS and peripheral nerves) or the musculoskeletal system. In the nervous system, the most common treatments are, ITB, Selective Dorsal Rhizotomy (SDR) [139], and selective neurotomy [140, 141]. SDR is mainly used for lower limb spasticity in $\mathrm{CP}$, and neurotomy, is restricted to decreasing over-activity in pure motor nerves.

The most common surgical intervention is, however, correction of the musculoskeletal system. This aims to decrease, eliminate or redirect overactive muscle forces, or at mobilizing, stabilizing or restoring balance in joints [142]. Surgery is often considered the last resort, though there is support for introducing this treatment option at an earlier stage [142].

\subsection{SUMMARY OF INTRODUCTION}

- Spasticity is a common sequel after lesions of the CNS.

- Spasticity is not debilitating per se, but rather may have both positive and negative effects on functioning. Only the negative effects of spasticity are indications for treatment, and always have to be weighed against any untoward effects of the intervention.

- In the rehabilitation process, a qualified evaluation of spasticity should comprise an evaluation of both the spasticity (quality, quantity, location, triggers) and its impact on the patient.

- An evaluation of spasticity must, as a matter of course, take into consideration the patient perspective. In addition, efficacy from a societal and health economic perspective is desirable, as it should influence resource optimization.

- Treatment has to be personalized, according to the symptoms of the individual patient, and a multidisciplinary team involved is necessary to achieve this. 


\section{AIMS}

Rehabilitation medicine as a medical specialty confesses to a holistic approach to assist patients optimize functioning and regain maximum ability to reintegrate in their social context. Applied to the topic of spasticity, this means that how spasticity interferes with the life of the individual is in focus, not the spasticity per se. As a clinical physiatrist, we always have the obligation to stay up-to-date with knowledge and contribute to an increasing understanding as to how we may provide the best treatment available within the economic limitations of public health-care.

The overall aim of this thesis is therefore to optimize care of spasticity. The specific research questions are:

1. How can we optimally evaluate spasticity management from the perspective of functioning?

Paper I, II, IV

2. Is therapeutic electrical stimulation for treatment of spasticity an effective and feasible method?

Paper IV

3. How can health economic analysis, fruitfully, be applied to the evaluation of spasticity management?

Paper III, IV

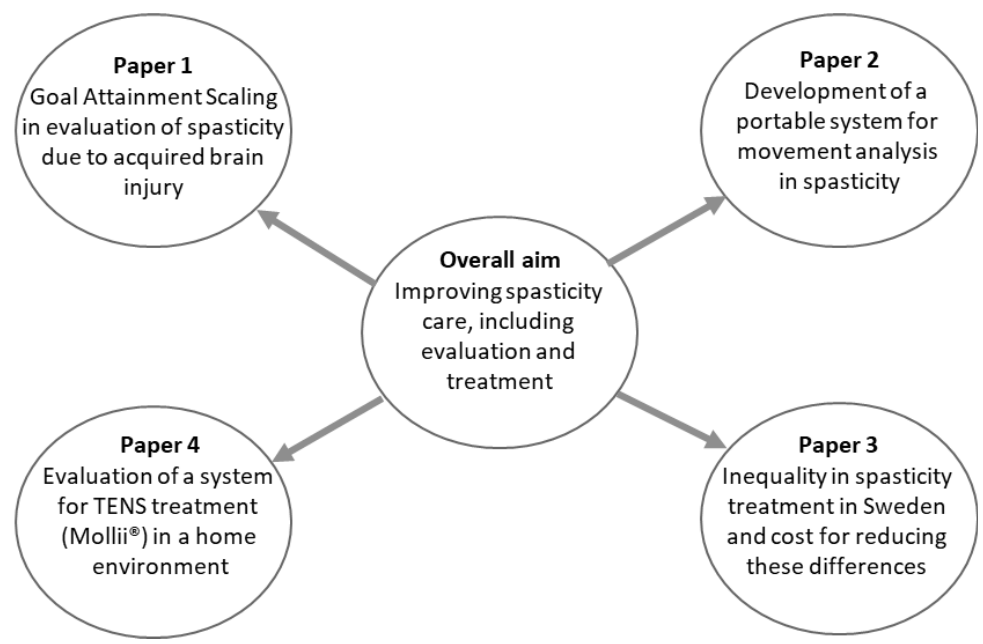

Figure 6: Overall aim and related papers included in the thesis. 
The aims may be further specified, as they pertain to each of the four research papers comprising this thesis:

\section{Paper I}

- Which are the advantages and disadvantages of using GAS as an outcome measure in patients with spasticity related to acquired brain injury (ABI) undergoing a rehabilitation program?

\section{Paper II}

- What is the level of accuracy of portable sensors as compared to a "gold standard" system with optoelectronic cameras?

- Is a modified Exposure Variation Analysis (EVA) a useful tool for assessing arm movements?

- May EVA be a useful tool for graphically describing the results of movement analysis after stroke?

Paper III

- Are there regional differences in BoNT-A treatment for spasticity in Sweden?

- Is current treatment with BoNT-A for spasticity reasonable from a healtheconomic perspective?

- What would the estimated cost for eradicating the differences in spasticity care in Sweden be?

\section{Paper IV}

- Can treatment with a therapeutic electrical stimulation system improve function and activity in persons with spasticity?

- Is such treatment feasible and safe? 


\section{OVERVIEW OF INCLUDED PAPERS}

In this thesis, I have utilized several approaches to assess different facets of spasticity. As the papers are very different, both in aim and methodology, the presentation will be consecutive for each paper, followed by an overarching discussion and conclusion. The first paper comprises a literature review, aimed at extracting information on how to optimize the use of GAS in spasticity evaluation. The second paper is validating whether a novel portable movement analysis system can evaluate aspects of function in a reliable way. The third paper is an analysis of public data on the use of BoNT-A in Sweden as an indicator for possible inequalities in spasticity care, using an healtheconomic approach to evaluate the consequences of this. The fourth paper, a randomized, double blind RCT, looks at the efficacy of TES embedded in a garment, in treating spasticity.

Regional ethic committees approved the papers involving study participants. For paper II this was the Regional Ethical Review Board of Umeå University (Dnr 09-120M) and for paper IV ethical approval was given by the Regional Ethical Review Board of Linköping (Dnr 2013/150-31). All participants signed a written informed consent. Paper 4, was pre-published online on ClinicalTrials.gov (trial no: NCT02261142). Paper I and III did not involve participants, and therefore did not need ethical approval. 


\section{Goal Attainment in eVAluation OF SPASticity (PAPER I)}

\subsection{INTRODUCTION}

GAS is increasingly used in research and in the clinic as a unique approach to capture the patient perspective on limitations and goals for intervention. We wished to investigate the experiences documented in the literature. Despite many years having passed since the instrument was initially constructed [64], it is only in the recent decade that it has been frequently used as an outcome in spasticity research. The aim of this literature review was to focus on the use of GAS in patients with ABI regarding its advantages, disadvantages and practical application.

\subsection{Method}

References for this review was identified by searches of PubMed and PsycINFO from January 1968 to March 2009, using the terms "goal attainment", "brain injury", "cerebral palsy", "rehabilitation" "stroke" and "trauma". Clinical studies (randomized controlled trials, observational studies, and case-control studies), case reports and review articles regarding the utilization of GAS during rehabilitation of ABI patients were selected and reviewed by the authors.

The objective of the review process was not to perform a conventional systematic review of the evidence, but to extract the most pertinent information on how GAS has been used in the ABI rehabilitation setting and to summarize some related observations. Conclusions of selected studies were therefore reported as presented in their respective publications. The authors also included some examples for goal-setting and scaling from their own clinical experience.

\subsection{Results}

The advantages and disadvantages in using GAS as an outcome measurement in spasticity after ABI was described. Strategies for implementing GAS in clinical practice and research were suggested. In summary, the findings were:

\section{Advantages with GAS:}

- May be used in heterogeneous populations (e.g. in a population with diverging functioning and health conditions).

- Not influenced by demographic factors (e.g. ethnicity, socio-demography or gender).

- Captures aspects not included in conventional instruments of activity and participation, e.g. ADL-instruments and instruments of HRQoL.

- Good content validity and reliability, as well as high sensitivity.

- Goal setting and goal evaluation may facilitate the rehabilitation process by enhancing motivation and the therapists understanding of the patient. 


\section{Disadvantages with GAS:}

- The use is time consuming (40-60 minutes at the initial testing and 10 minutes for re-test [143]).

- There is a need for a learning period to set adequate and realistic goals.

- There are a number of pitfalls in goal setting, e.g. lacking a set time-frame for evaluation, ambiguous goals, multiple goals fused into one. All of these pitfalls make evaluation difficult (examples of difficulties in table 1).

\section{Practical aspects:}

- In order to capture relevant goals, it may be useful to use COPM [144], ICF [72, $145]$ or publications listing goals found to be appropriate [95, 146].

- Goals should be challenging to achieve, but still realistic for the individual patient.

- Goals should be explicitly stated, e.g. "walking stairs, one floor with handrail for left arm and without resting".

- The time-frame has to be specified, i.e. when goals are intended to be achieved and therefore to be evaluated.

- The resources required to achieve a goal has to be available.

\section{Controversies regarding GAS:}

- Choice of statistical method. The original scale is using T-score, thereby normalizing a non-normal distribution, to be able to use parametric statistics. An alternative approach is to use the raw score, also referred to as the change score, thereby not manipulating data, but instead having the disadvantage of using nonparametric statistics.

\subsection{Conclusion}

The review yielded a number of concrete advantages and disadvantages of using GAS for ABI patients with spasticity. GAS measures clinically meaningful change in functioning. This is especially important in rehabilitation of patients with disability related to ABI, as these patients display huge variations in in this respect. It has advantages compared to more standardized assessments, capturing the problem of the individual patient and transforming these into treatment goals. There are methodological challenges, both in the application of the instrument and in the statistical analysis, which needs consideration before using the instrument. When choosing which version of GAS to use, the purpose of measurement is what matters. We suggest the 5point scale for clinical practice. The 6-point scale, with a -3 for deterioration, may be preferred for research purposes, in spite of change score being used for evaluation, instead of the original T-score. From the review, it is clear that before using the instrument in research, it is essential to consider the need of a learning-period and to decide on what statistical approach to use. 


\section{VALIDATION OF A SYSTEM FOR PORTABLE MOVEMENT ANALYSIS (PAPER II)}

\subsection{INTRODUCTION}

Health conditions affecting CNS often impede motor function. Interventions to retrain motor function, e.g. gait or dexterity, is a central part of rehabilitation. Chiefly, various clinical assessments are used for evaluation, e.g. dexterity with box and block test. These can document an improvement in task completion, but cannot describe the actual process of performance. The "gold standard" for movement analysis, especially gait, is in a gait laboratory with multiple optical cameras and reflective markers placed on the body in order to register and analyze 3-dimensional body motion. The disadvantage with this is its being time-consuming, location-dependent and expensive. With technologic progress, small portable inertial sensors, which measures 3-dimensional motion have been developed and tested, mainly for gait, showing promising results. In this study, we developed and validated a method including motion analysis of a set of standardized arm activities. Furthermore, there are several mathematical methods available for analysis of movement data. The use of Exposure Variation Analysis (EVA) for graphically describing the results, regarding effectiveness in permitting evaluation of the actual process of performance.

\subsection{METHOD}

The participants comprised ten healthy volunteers, recruited from hospital staff, without any previous arm pain or arm disability. In addition, one participant was included who had suffered a stroke 5 years prior to the study, for exploring feasibility of the instrument in people with disability. This subject had a left-sided hemiparesis, with the left hand mainly used for support in bimanual activities.

\subsubsection{Intervention}

Participants performed four different arm activities, simultaneously measured with the portable motion system and with a standard camera-based optoelectronic system (Coda mpx30, CodaMotion, Charnwood Dynamics Limited).

Sensors for the portable system were placed in the middle of each segment of the arm, with the optoelectronic active markers placed on these sensors to secure an identical placement (Figure 7). In order to calibrate the systems, every activity started with a swift arm pronation/supination. The portable sensors transmitted the signal wirelessly to a PC, allowing full mobility in performed activities. Due to different sampling frequencies in the optoelectronic system and the portable system, the frequency for the latter was down-sampled from 128 to $100 \mathrm{~Hz}$ to match the optoelectronic system. For details on this procedure, see paper II. 

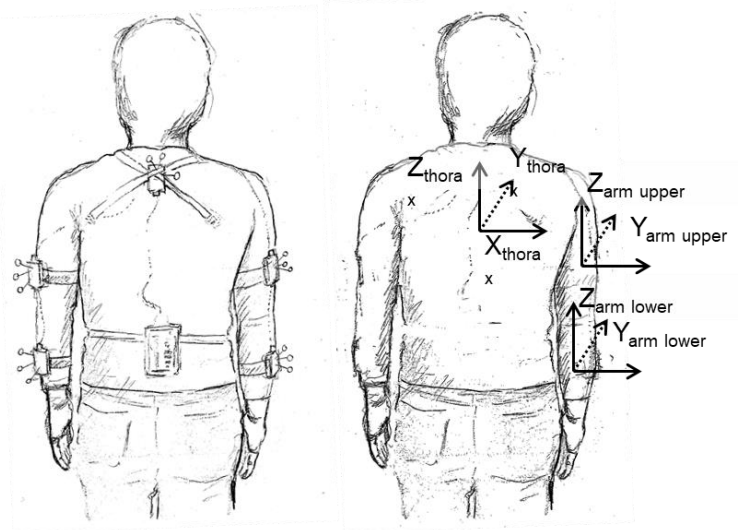

Figure 7: Placement and movement planes of the sensors.

Four arm activities were defined (table 2), reflecting a wide variation in speed, complexity and movement pattern.

Table 2: Description of movement tasks performed in paper II.

\begin{tabular}{|c|c|}
\hline Activity & Description \\
\hline Cone & $\begin{array}{l}\text { A lifting and dropping task, where the subject moved } 4 \text { cones from } \\
\text { one lower level on a table to a higher in a forward direction. The } \\
\text { movement was slow and repetitive. }\end{array}$ \\
\hline Throw & $\begin{array}{l}\text { A throwing and catching task that mainly involved elbow flexion. } \\
\text { The subjects started with the arm in a neutral position, and then } \\
\text { threw a small bag (filled with peas) } 5 \text { times, catching it between } \\
\text { throws. This gave a fast accelerating/decelerating movement. }\end{array}$ \\
\hline $\begin{array}{l}\text { Coordination } \\
\text { task } 1 \text { (CT1) }\end{array}$ & $\begin{array}{l}\text { Hands moved from the starting position to the top of the head, to the } \\
\text { shoulder, clapping back of hands together, moved hands to the knee } \\
\text { and then to the toe. This movement was complex, involving all joints } \\
\text { including supination/pronation and a large movement range. }\end{array}$ \\
\hline $\begin{array}{l}\text { Coordination } \\
\text { task } 2 \text { (CT2) }\end{array}$ & $\begin{array}{l}\text { The hands moved from the starting position to the ears, to the eyes } \\
\text { and then to the mouth. This sequence gave small, coordinated and } \\
\text { slow movements. }\end{array}$ \\
\hline
\end{tabular}

Exposure variation analysis (EVA) was applied to capture movement function of the arms by illustrating how elbow and shoulder joint angle and joint angle velocity were distributed in time and magnitude for different movement tasks (each task giving a specific pattern). The registered signal, from both the optoelectronic system and the portable system, was divided into consecutive intervals of 0.1 seconds. The signal 
magnitude and the number of consecutive intervals spent at that magnitude was used for the analysis. The EVA was modified with the exposure time divided into logarithmic intervals and the signal magnitude divided into linear intervals.

\subsubsection{Statistics}

Bland- Altman statistics was used to investigate systematic and proportional error effects when comparing data from the custom developed system with data from the reference system. The repeatability of the components of the Angular EVAs was assessed using an interclass correlation coefficient (ICC) with a two-way mixed model with absolute agreement. Single ICC represents the correlation between single measures for the same subject, where ICC $>0.40$ indicates moderate repeatability and ICC $>0.70$ indicates high repeatability [147].

\subsection{RESULTS}

A good congruence was found in comparison between the portable and the reference system, illustrated in figure 8. Interclass correlations between systems showed good to excellent repeatability for all movements, except for pronation-supination in the elbow, which showed moderate to good repeatability (table 4, in paper II). A small drift along the gravity vector occurred in the curves from the portable system as compared to the optoelectronic system during the CT-tasks. This was small, but direction-specific, giving a systematic error (table 3 , in paper II).
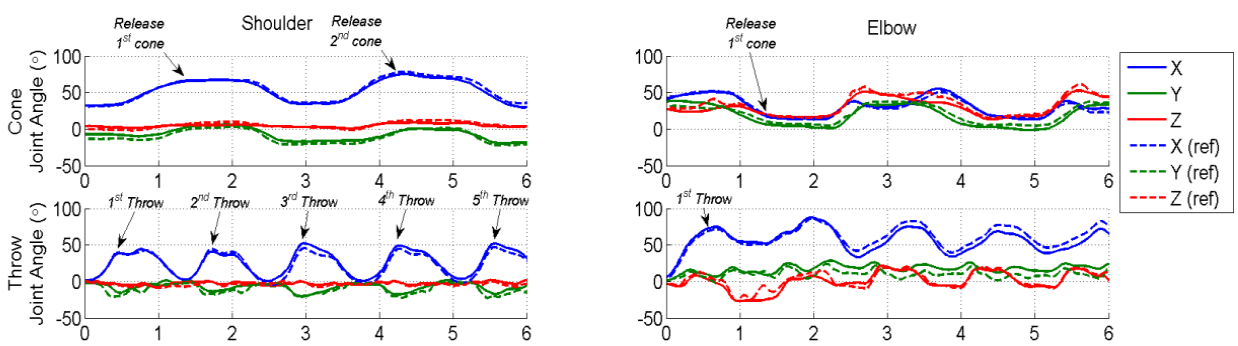

Fig 8: Example of joint angles. This graph illustrates elbow- and shoulder angle from one participant during two different movements (Cone and Throw). The portable system is shown with thick lines and the reference system with dashed lines. The colors illustrates movements in different planes; blue for the sagittal plane, green for the frontal plane and red for the horizontal plane.

EVA was able to discriminate between the four different activities in the different movement directions. Figure 9 and 10 illustrates how the joint angle and joint angle velocity, and especially in combination, shows a distinct pattern for each activity. 

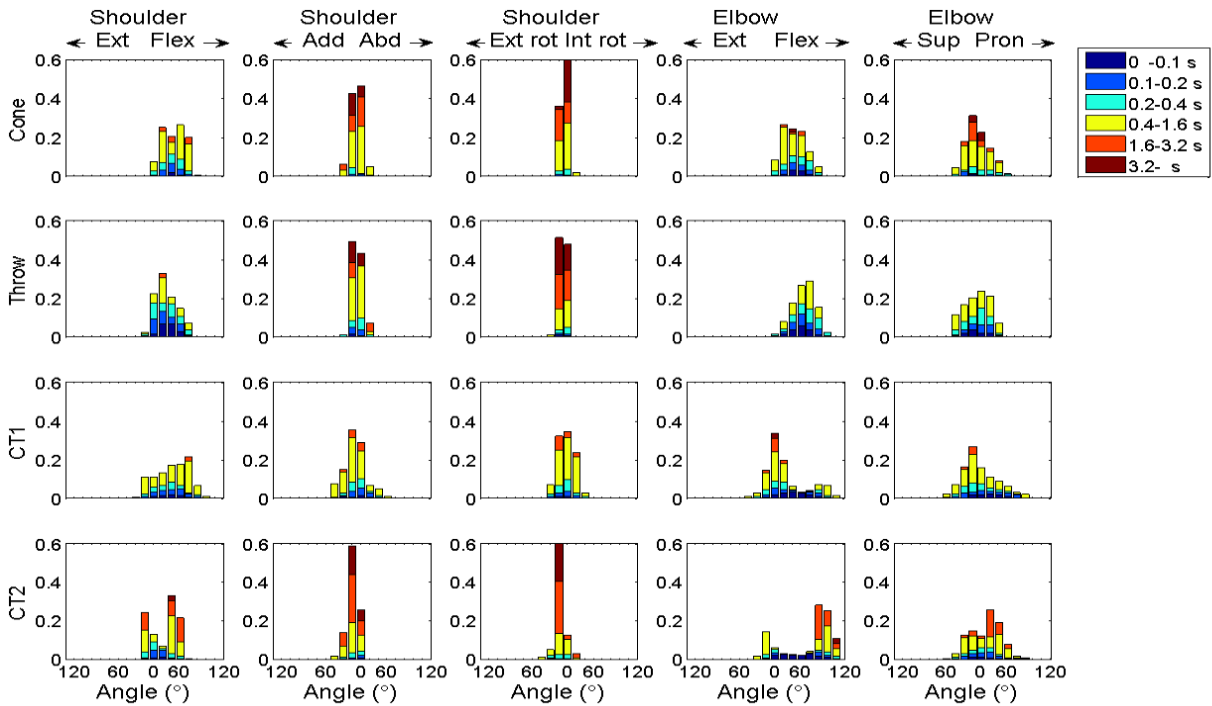

Figure 9: Group mean EVA histograms of the shoulder and elbow joint angles during the four test conditions. The graph illustrates analyzed data from the portable system. The $\mathrm{x}$-axes represents joint angle, and the y-axes represents percent of the total time that the elbow or shoulder was held in the specific angular range. The length of duration times, spent in each magnitude level, described in the legend.
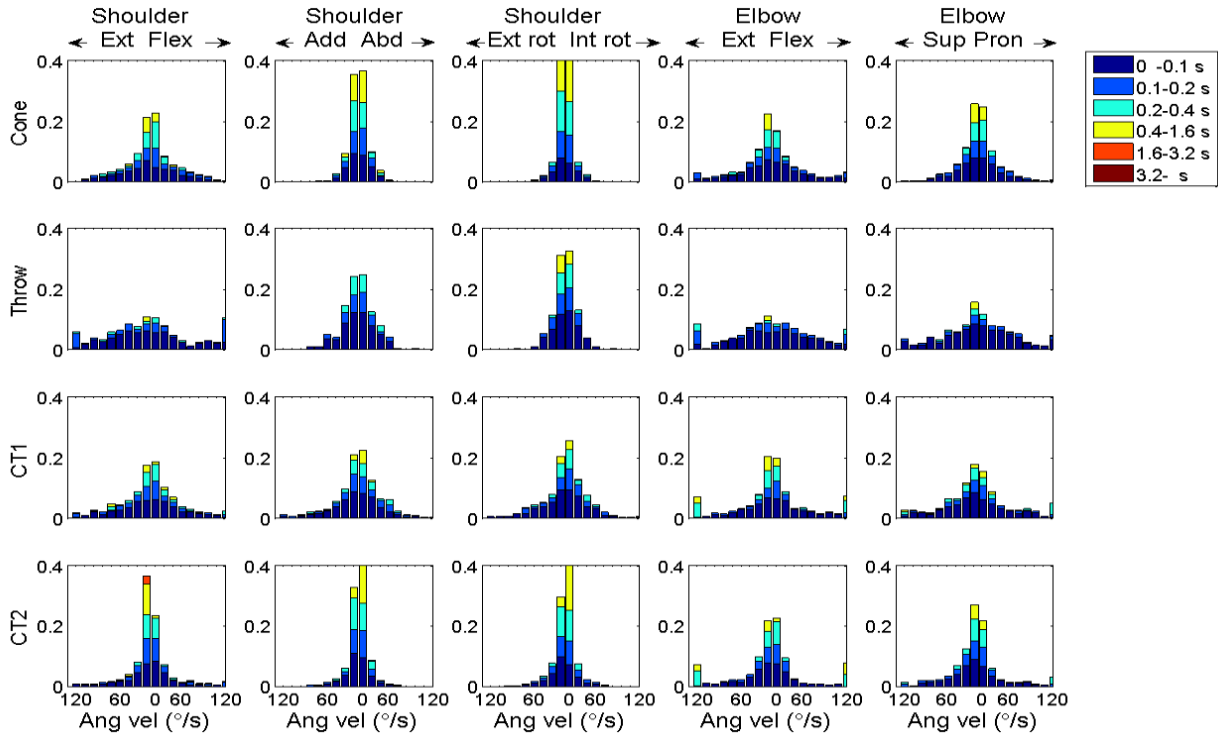

Figure 10: Group mean EVA histograms describing the shoulder and elbow joint angle velocity pattern during the four tasks. The graph illustrates analyzed data from the portable system. The $x$-axes represents joint angle velocity, and the y-axes represents percent of the total time that the elbow or shoulder was kept in the specific angular velocity range. The length of duration times, spent in each magnitude level, described in the legend. 
EVA performed on data from the participant with a hemiparetic stroke showed a distinct pattern with decreased joint angles and a decreased angle joint velocity in the paretic arm. Figure 11 illustrates this for the cone activity.
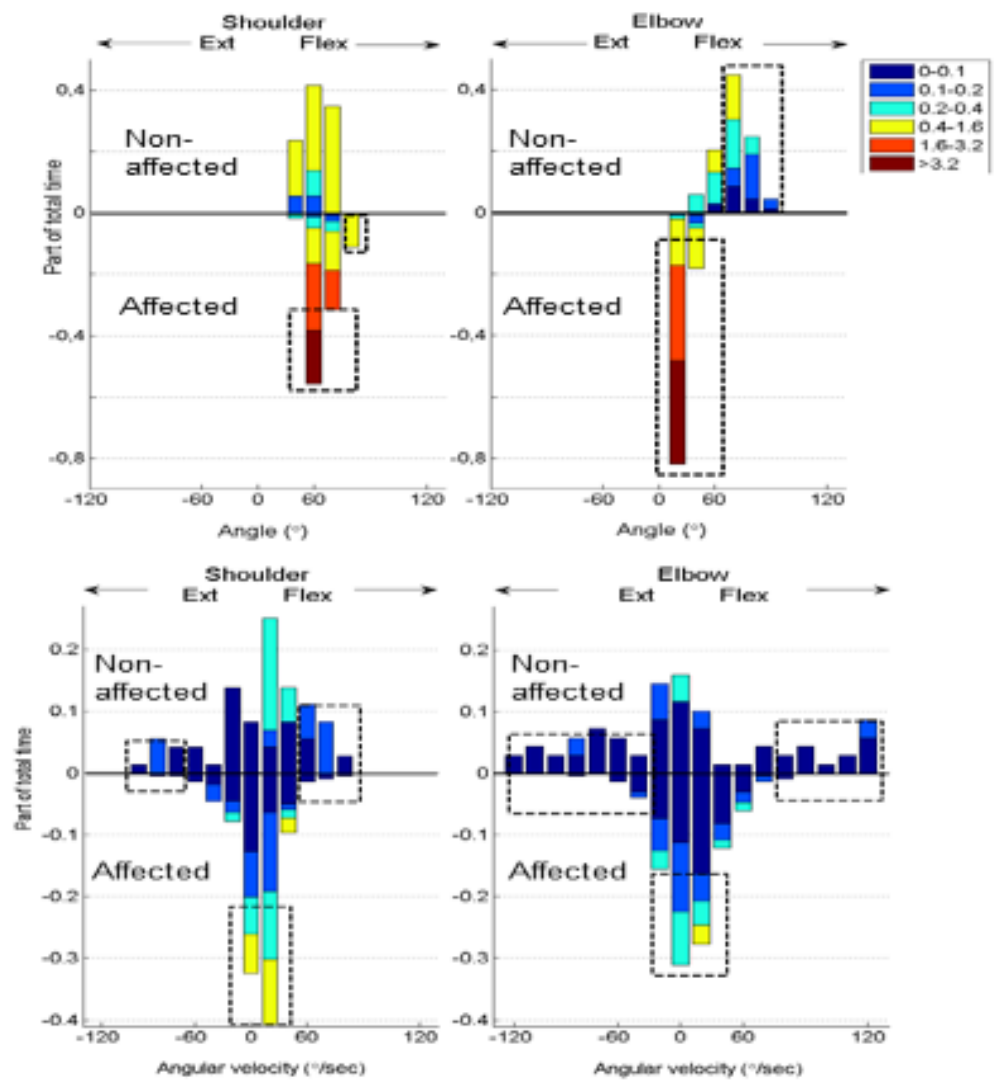

Figure 11: EVA histograms for joint angles (A), and joint angle velocity (B) from one patient with spastic hemiparesis due to stroke. Joint angle and joint angle velocity for the cone activity is shown for the shoulder and elbow. Positive bars are the unaffected arm and negative bars are the paretic arm. 


\subsection{Methodological discussion and limitations}

The portable system was comparable to the reference system regarding accuracy, but both systems had different advantages and disadvantages. As an example, data from one participant was omitted due to loss of information from the reference system, as movements blocked the visual field of the cameras. In the portable system, there were no missing data, but on the other hand, we found a drift of the signal, which needs adjustment if used for longer registrations.

The study group was small and recruited from hospital staff, thus not representing a normal population.

The use of EVA for presenting results was exploratory and promising regarding usefulness, but needs confirmation in coming studies of both healthy persons and persons with movement disabilities, as well as further development on how to present quantitative data in ways that can be interpreted clinically.

\subsection{Conclusion}

The "gold-standard" for movement analysis, i.e. an optical system with stationary cameras is well documented in its precision and usefulness for capturing abnormalities in movement patterns. The disadvantage is it being expensive, time-consuming and restricted to a laboratory environment. In contrast, a portable movement system has the possibility to overcome all of these problems, but also giving new opportunities concerning more adaptive, long-term measurements mimicking the every-day life of our patients. In this first study on using this portable movement system in arm movements, we saw that the measurements were valid, with a good to excellent correlation compared to the "gold-standard" system. The study also verified EVA to be a useful tool for presenting data as it clearly could discriminate between different types of arm activities, as well as the difference between the affected and non-affected arm in the participant with PSS. There is however a need for further developments in handling the drift of the system and in the presentation of data both graphically and quantitatively. 


\section{INEQUALITY IN SPASTICITY CARE, AN HEALTH-ECONOMY STUDY (PAPER III)}

\subsection{INTRODUCTION}

As has already been stated, spasticity is one of the most frequent sequels of health conditions involving the CNS [27]. The treatment of spasticity has developed over the last decades with new treatment options. For focal spasticity treatment, BoNT-A is the drug treatment of choice. It is well documented, scientifically as well as in consensus documents $[132,148]$. In Sweden, the concept of equality in access and quality of health-care is an explicit political goal. In spite of this, inequality in healthcare is a wellknown problem, related to both socioeconomic and regional differences [149-152]. This study intended to see if spasticity care differed between parts of Sweden, using BoNTA treatment as an indicator. We also wanted to calculate the cost for equalizing any difference in the treatment of spasticity and the evidence for cost-effectiveness.

\subsection{Method}

The science of health-economy typically deals with uncertainties in data. There are different ways to cope with these uncertainties. In this paper, we use conservative assumptions and try to compensate for these in a sensitivity analysis, testing alternative scenarios. To aid the reader in the understanding of this uncertainty, table 3 lists the assumptions and the chosen strategies for handling these issues.

In choosing data sources for the study, preferably references from Sweden or the other Nordic countries were identified. If no sufficiently good studies from the Nordic countries were available, studies from countries with similar socio-economic situation were used. The papers on prevalence of diseases, spasticity and disabling spasticity are referenced in table 4.

Prevalence of disabling spasticity by region was calculated from population data for the year 2013 published by Statistics Sweden (Statistiska Centralbyrån) [153]. We assumed the prevalence of disabling spasticity to reflect the proportion of patients eligible for BoNT-A treatment [154].

Data on regional use of BoNT-A was acquired from IMS Health (pharmacy distribution to hospitals and institutions, 2013). The hospital part of BoNT-A use was considered to comprise all spasticity treatment, as most spasticity treatment is performed in hospitals. Therefore, the BoNT-A sales on prescription to non-hospital centres were not included. In four county councils (Uppsala, Östergötland, Blekinge and Stockholm) BoNT-A use for spasticity treatment in adult spasticity were validated, showing that the proportion of the hospital used BoNT-A for spasticity, ranged from $32 \%$ to $49 \%$. Consequently, in the base case analysis, we used a mean of $40 \%$. 


\begin{tabular}{|c|c|}
\hline Assumption/uncertainty & Rationale for chosen strategy \\
\hline $\begin{array}{l}\text { Uniform regional prevalence of } \\
\text { diseases, spasticity and disabling } \\
\text { spasticity }\end{array}$ & $\begin{array}{l}\text { Sweden is relatively homogeneous concerning } \\
\text { ethnical and sociodemographic background. }\end{array}$ \\
\hline $\begin{array}{l}\text { The prevalence of disabling spasticity } \\
\text { reflect the proportion of patients } \\
\text { eligible for BoNT-A treatment }\end{array}$ & $\begin{array}{l}\text { This is probably an overestimation of the } \\
\text { population, as it includes both focal and } \\
\text { generalized spasticity, where only the focal type } \\
\text { is eligible for BoNT-A treatment. }\end{array}$ \\
\hline $\begin{array}{l}\text { The hospital part of BoNT- A use was } \\
\text { considered to comprise all spasticity } \\
\text { treatment }\end{array}$ & $\begin{array}{l}\text { Swedish health-care is publically funded, and } \\
\text { private care for spasticity is close to non-existing, } \\
\text { except for the Stockholm county. For the latter, a } \\
\text { validation was performed, taking in account the } \\
\text { private actors. }\end{array}$ \\
\hline $\begin{array}{l}\text { Conversion ratio between the different } \\
\text { BoNT-A brands is lacking }\end{array}$ & $\begin{array}{l}\text { For the calculations we needed the total volume } \\
\text { of BoNT-A used for spasticity and the article by } \\
\text { Ravenni [155] was chosen as a new, unbiased } \\
\text { source for this conversion between brands. }\end{array}$ \\
\hline $\begin{array}{l}\text { Patients receive three treatment cycles } \\
\text { annually }\end{array}$ & $\begin{array}{l}\text { This was based on data from one county. If this } \\
\text { varies between the counties, it can affect the } \\
\text { calculations. Has to be considered in future } \\
\text { studies. }\end{array}$ \\
\hline $\begin{array}{l}\text { The cost of spasticity (i.e. the savings } \\
\text { in cost by reducing spasticity severity) }\end{array}$ & $\begin{array}{l}\text { This is based on two articles, on stroke and MS, } \\
\text { respectively. This cost is generalized to all } \\
\text { conditions. The most conservative cost estimation } \\
\text { was chosen, and a sensitivity analysis was } \\
\text { performed reducing the cost reduction of } \\
\text { decreasing spasticity down to } 25 \% \text { of the base } \\
\text { case. }\end{array}$ \\
\hline $\begin{array}{l}\text { The county with the highest use of } \\
\text { BoNT-A is closest to optimal level of } \\
\text { treatment }\end{array}$ & $\begin{array}{l}\text { Since there is a lack of spasticity treating } \\
\text { physicians, a lack of guidelines (except in the } \\
\text { county with highest use) and a pressure for } \\
\text { reducing costs in the health-care system it is } \\
\text { reasonable to assume an under-utilization in } \\
\text { BoNT-A treatment. }\end{array}$ \\
\hline
\end{tabular}

Table 3: Assumptions and uncertainties in paper III, and strategies to cope with these.

In Sweden, three different brands of BoNT-A are available. No agreed on equipotency among these products exist. For the purpose of cost calculation, the products needed conversion to estimated equivalent doses. This calculation was based on the publication of Ravenni et al. [155]. We assumed three treatment cycles/patient and year on average (data from Östergötland), and this treatment frequency was extrapolated to the whole population.

Total intervention costs for BoNT-A treatment, including healthcare visits and drug costs, were gathered from regional healthcare tariffs [156]. Costs associated with spasticity were derived from publications on stroke [35] and MS [157]. In stroke, direct costs during the first year post- stroke were 4 times higher in patients with spasticity 
compared to patients without. The difference amounted to 62353 PPP\$ (Purchasing Power Parities US dollar, 2003 value), equivalent to 72167 EUR (2014 value). In MS, the total annual cost (comprising direct and indirect costs) of severe spasticity in MS was 180759 EUR, while the cost for moderate and mild spasticity was estimated at 136 025 and 75239 EUR, respectively [157]. Assuming a complete causal relationship between spasticity and costs, the cost difference between severity grades of spasticity was 60786 EUR (mild-moderate) and 44554 EUR (moderate-severe) per year. Using the most conservative estimate, transition between severity grades of spasticity was associated with a cost difference of 45000 EUR per year in the calculations.

\subsubsection{Statistics}

As the calculations included a number of simplifying assumptions (table 3), we performed one-way sensitivity analyses. To account for potential regional variation in the prevalence of disabling spasticity, inpatient statistics for the year 2013 from The National Board of Health and Welfare and regional prevalence of the major underlying conditions of spasticity was collected (ICD-10 codes; G35, G80, I61, I63, I64, S06, $\mathrm{S} 14, \mathrm{~S} 24$ and S34). The regional relative mean prevalence of all conditions was adjusted relative the reference-derived estimates. To control for the assumption on treatment gap, the healthcare region with the highest BoNT-A use (treatment level of 50\% for disabling spasticity) was compared to $30 \%$ in the rest of the healthcare regions (corresponding to the lowest proportion in validated county councils) instead of the averaged $40 \%$. Finally, as the relationship between spasticity and costs was a calculation from results in only two papers, the influence on costs by reducing spasticity was depreciated, gradually lowering the association down to $25 \%$ of the base case scenario. From this, we calculated the incremental cost for each scenario. In addition, the proportion of the treated population required to transfer between spasticity severity grades for cost neutrality is given.

\subsection{Results}

Table 4 presents the prevalence of included diseases and the prevalence of spasticity and disabling spasticity. In paper III, table 2, prevalence is applied on regional populations, thereby illustrating the number of individuals with disabling spasticity in each health-care region in Sweden. 
Table 4. Epidemiology of spasticity

\begin{tabular}{llll}
\hline Condition & Prevalence condition & Prevalence spasticity & $\begin{array}{l}\text { Prevalence disabling } \\
\text { spasticity }\end{array}$ \\
\hline Stroke & $715 / 100,000[158]$ & $31 \%[7,10,159]$ & $12 \%[7,159]$ \\
MS & $190 / 100,000[25]$ & $66 \%[160]$ & $26 \%[160]$ \\
CP & $170 / 100,000[161]$ & $85 \%[162,163]$ & $22 \%[164]$ \\
SCI & $32.3 / 100,000[165,166]$ & $65 \%[24]$ & $27 \%[24]$ \\
TBI & $150 / 100,000[167]$ & $35.3 \%[168]$ & $19 \%[11]$ \\
\hline
\end{tabular}

As the individuals with disabling spasticity are the target group for treatment, the proportion of this population treated with BoNT-A in each health-care region was calculated and varied from $9 \%$ to $23 \%$. Table 5 presents data for each health-care region.

Table 5. Regional BoNT-A use. All BoNT-A drugs have been converted to abobotulinumtoxinA equivalents, according to Ravenni et al [155].

\begin{tabular}{lllll}
\hline Health Care region & $\begin{array}{l}\text { Total BoNT-A } \\
\text { use, all } \\
\text { indications } \\
(\text { dose/100,000) }\end{array}$ & $\begin{array}{l}\text { Hospital use } \\
\text { of BoNT-A } \\
(\text { dose/100,000) }\end{array}$ & $\begin{array}{l}\text { Mean hospital } \\
\text { use of BoNT-A } \\
\text { for spasticity } \\
\text { (dose/100,000) }\end{array}$ & $\begin{array}{l}\text { Proportion of } \\
\text { disabling } \\
\text { spasticity } \\
\text { population } \\
\text { treated }\end{array}$ \\
\hline Stockholm-Gotland* & 767 & 135 & 54 & $9 \%$ \\
Western & 255 & 145 & 58 & $9 \%$ \\
South Eastern* & 287 & 235 & 94 & $15 \%$ \\
Örebro-Uppsala* & 292 & 245 & 98 & $16 \%$ \\
Northern & 370 & 330 & 132 & $21 \%$ \\
Southern* & 418 & 365 & 146 & $23 \%$ \\
\hline
\end{tabular}

* Comprising a county council validated for hospital BoNT-A use for adult spasticity

1) Source: IMS Health 2013.

2) Assuming a mean share of $40 \%$ of total hospital BoNT-A use for spasticity (see Methods section).

${ }^{3)}$ Based on the assumption of 3 annual equipotent doses of BoNT-A per patient.

Table 6 presents the incremental cost for reaching regional equity, based on the assumption that the region with the largest use of BoNT-A for spasticity is closest to a steady-state level of treatment. The total increased cost for Sweden was to 9424755 EUR (2014).

The sensitivity analysis showed that a reduction in severity grade of spasticity, in the $25 \%$ scenario, would save 11250 EUR, instead of the base case, 45000 EUR. In this case, cost neutrality requires that $47 \%$, instead of $12 \%$, of treated patients had to change their spasticity severity grade to reach cost neutrality (table 7). 
Table 6. Incremental cost for regional treatment equity.

\begin{tabular}{llll}
\hline Health care region & $\begin{array}{l}\text { Total incremental } \\
\text { number of } \\
\text { equivalent doses }\end{array}$ & $\begin{array}{l}\text { Total incremental } \\
\text { number of patients to } \\
\text { treat }^{1)}\end{array}$ & $\begin{array}{l}\text { Total incremental cost } \\
\text { 2) (EUR 2014) }\end{array}$ \\
\hline Stockholm-Gotland & 2043 & 681 & $3,603,627$ \\
Western & 1691 & 564 & $2,983,858$ \\
South Eastern & 527 & 176 & 929,295 \\
Örebro-Uppsala & 958 & 319 & $1,690,826$ \\
Northern & 123 & 41 & 217,149 \\
Southern & - & - & - \\
Total & 5342 & 1781 & $9,424,755$ \\
\hline
\end{tabular}

${ }^{1)}$ Assuming 3 equipotent doses of BoNT-A per patient and year.

${ }^{2}$ Based on the intervention cost of 1764 EUR (16049 SEK) per patient for BoNT-A spasticity treatment in the outpatient care setting 2014. Source: Regional price list Uppsala County council 2014.

Table 7. Sensitivity analyses.

\begin{tabular}{lllll}
\hline Scenario & $\begin{array}{l}\text { Total } \\
\text { incremental } \\
\text { number of } \\
\text { equivalent } \\
\text { doses }\end{array}$ & $\begin{array}{l}\text { Total } \\
\text { incremental } \\
\text { number of } \\
\text { patients to } \\
\text { treat }\end{array}$ & $\begin{array}{l}\text { Total } \\
\text { incremental } \\
\text { cost, } \\
\text { intervention } \\
\text { (EUR 2014) }\end{array}$ & $\begin{array}{l}\text { Proportion of } \\
\text { incremental treated } \\
\text { number required to } \\
\text { change severity grade } \\
\text { for cost neutrality }\end{array}$ \\
\hline Base case $^{1)}$ & 5,342 & 1,781 & $9,424,755$ & $12 \%$ \\
Adjusted prevalence $^{2)}$ & 7,272 & 2,424 & $12,828,858$ & $12 \%$ \\
Max. treatment gap $^{3)}$ & 9,869 & 3,290 & $17,411,540$ & $12 \%$ \\
Association between $^{4)}$ & & & & \\
spasticity and costs $^{4)}$ & 5,342 & 1,781 & $9,424,755$ & $16 \%$ \\
$75 \%$ & 5,342 & 1,781 & $9,424,755$ & $24 \%$ \\
$50 \%$ & 5,342 & 1,781 & $9,424,755$ & $47 \%$ \\
$25 \%$ & & & & \\
\hline
\end{tabular}

${ }^{1}$ Base case; $40 \%$ of hospital BoNT-A use for spasticity, no regional variation in spasticity, total intervention cost (1,764 EUR), full causal relationship between severity grade of spasticity and associated costs $(45,000$ EUR)

${ }^{2)}$ Prevalence adjusted according to regional in-patient statistics for underlying conditions (the National Board of Health and Welfare (2013).

${ }^{3)}$ Assuming a maximum treatment gap, where the healthcare region with the highest BoNT-A use (Southern) has a higher treated proportion (50\%) of estimated disabling spasticity than the rest of the health care regions $(30 \%)$.

4) Effects of decreased influence on the costs (45,000 EUR, see Method section) associated with transition between severity grades of spasticity. 


\subsection{Methodological discussion AND Limitations}

Due to a scarcity of relevant publications, a number of assumptions were made, as discussed in the methods section.

BoNT-A brands have different potency and no consensus exist on what is equipotent doses. In spite of this, for the calculations we needed the total volume of BoNT-A used for spasticity and therefore we had to fuse the volumes of the different brands. The article presents the rationale for this choice.

The lack of available data regarding cost versus spasticity severity also needed methodological consideration. This was handled by using the most conservative cost estimation for changing severity grade of spasticity. In addition, a sensitivity analysis was performed looking at the robustness of the results.

The increased cost for equalizing the use of BoNT-A, was based on the assumption that the highest level of BoNT-A use also reflects the optimal level. This assumption seems reasonable, as there is nationally a lack of physicians skilled in BoNT-A treatment, and the fact that the highest using region is the only one with a regional guideline defining the role of BoNT-A treatment for spasticity.

\subsection{Conclusion}

Regarding the question of inequlity in spasticity treatment with BoNT-A, the study showed that there are large differences in Sweden. The county with the highest use used $270 \%$ more than the county with the lowest use.

Regarding the cost for eliminating this inequality, assuming that the highest degree of BoNT-A use in disabling spasticity is closest to the optimal level, the cost for reaching equality would be approximately 9.4 million EUR.

Concerning cost-effectiveness of BoNT-A treatment for spasticity the study found strong support for its cost-effectiveness. The expected efficacy of BoNT-A treatment according to Doan et al [51], showed at least a $45 \%$ probability for reduction in disability grade. Cost neutrality can be, in the base case scenario, obtained even with only $12 \%$ responder rate. When lowering the cost reduction in the sensitivity analysis to 11250 EUR, the $47 \%$ responders needed for cost neutrality averages the expected percentage of responders.

This study is in line with other publications confirming cost-effectiveness in treating spasticity with BoNT-A [51, 169, 170] and can support the hypothesis that there is a large inequality in spasticity care in Sweden, regarding BoNT-A use, a matter that needs attention and common guidelines for care. 


\section{EVALUATION OF A COMPREHENSIVE SYSTEM FOR TES TREATMENT OF SPASTICITY (PAPER IV)}

\subsection{INTRODUCTION}

TES has an effect on reducing spasticity [115, 171-177]. This was recently confirmed in a review on PSS and TES [178]. In recent years, a commercial application for selfadministration of TES has appeared. It is marketed towards patients with spasticity, as a complete package with TES-equipment, a garment with integrated electrodes, spasticity assessment, testing for stimulation settings and a set of recommended individualized training exercises. Effect of this system was based on only anecdotal evidence.

Our intention with this study was to evaluate this application for use in the home, without the need for therapist involvement in the daily treatment. The aims were to evaluate efficacy, feasibility, safety and cost-effectiveness of the equipment as it is presented to the consumers.

\subsection{Method}

The study was a randomized, controlled trial with a crossover design. The target group for the study comprised participants with spasticity, due to stroke or CP interfering with daily life, listed at one of the two collaborating rehabilitation units. The participants had to have clinically confirmed spasticity according to Ashworth measurement, some preserved walking ability, being 18 years of age or older, and being able to understand the treatment and evaluations used. In addition, for post-stroke patients, two years should have elapsed post stroke to avoid spontaneous recovery affecting the result of the study. Exclusion criteria were concomitant disease that could interfere with treatment, described in table 8, and/or BoNT-A in the preceding four months or during the study.

Table 8: Exclusion criteria.

\begin{tabular}{|l|}
\hline Exclusion criteria \\
\hline Electronic devices \\
Ventriculoperitoneal shunt \\
Arrhythmia \\
Myocardial infarction or unstable angina pectoris \\
Symptomatic arterial hyper- or hypotension \\
Cancer under treatment \\
Unstable psychiatric disease \\
Lung disease, affecting daily life \\
Unstable epileptic disease \\
Orthopedic surgery within a year \\
Obesity with BMI > 35 \\
Severe infectious disease \\
Pregnancy \\
\hline
\end{tabular}




\subsubsection{Assessments and outcome}

The theoretical framework for choosing outcome measurements was based on ICF [82]. The intention was to have instruments focusing on activity and HRQoL, thereby capturing activities important in daily life and relevant to the treatment.

\section{Disease severity}

For CP, we used the gross motor function classification system (GMFCS), being the "gold standard" for describing differences in functioning, mainly from a mobility perspective. In the post-stroke population, the National Institutes of Health Stroke Scale (NIHSS) was preferred, a scale mostly used in early evaluation of stroke as an instrument for prognosticating outcome.

\section{Assessment of spasticity}

Muscle tone was assessed by Modified Ashworth scale (table 9). For the presentation, we used the sum score of the 20 measured muscles. Modified Penn Spasm Score and Clonus Score was also registered [179] as well as range of motion (ROM) using a standard metal goniometer.

Table 9: Modified Ashworth scale used in the study.

\begin{tabular}{|c|c|}
\hline & Description of Ashworth level \\
\hline $\mathbf{0}$ & No increase in muscle tone \\
\hline 1 & $\begin{array}{l}\text { Slight increase in muscle tone, manifested by a catch and release or by minimal } \\
\text { resistance at the end of the range of motion when the affected part(s) is moved in } \\
\text { flexion or extension }\end{array}$ \\
\hline 2 & $\begin{array}{l}\text { Slight increase in muscle tone, manifested by a catch, followed by minimal } \\
\text { resistance throughout the remainder (less than half) of the ROM }\end{array}$ \\
\hline 3 & $\begin{array}{l}\text { More marked increase in muscle tone through most of the ROM, but affected } \\
\text { part(s) easily moved }\end{array}$ \\
\hline 4 & Considerable increase in muscle tone, passive movement difficult \\
\hline 5 & Affected part(s) rigid in flexion or extension \\
\hline
\end{tabular}

\section{Change in arm-hand ability}

The Action Research Arm Test (ARAT) [180, 181] was selected, with addition of the two first tasks of the Wolf Motor Function Test (WMFT) for active abduction of the shoulder joint [182]. The combination of ARAT and WMFT was expected to capture the large variation in function. 


\section{Change in mobility}

As gait performance differed among subjects, a test that could be performed even with poor walking ability was needed. Among the different tests possible, the 10-meter walking test, divided into the fast gait test (FGT) and comfortable gait test (CGT) [183], was chosen. From these tests, velocity, cadence and stride length were calculated. For more complex transfers, the Timed Up \& Go (TUG), was added to the protocol. Whether to allow walking aids and/or orthoses when measuring gait ability is a controversy. Apart from the obvious standpoint that a measurement of an ability should mimic ability in everyday life, there is also evidence that the use of aids does not change outcome [184]. Therefore, the use of walking aids and orthoses were permitted, although a recent paper suggest that fast gait barefoot has higher reliability [185].

\section{Goal attainment scaling}

GAS was primary outcome in the study and as we did not expect any deterioration, the original scale with the starting point as -2 was chosen (table 10).

Table 10: GAS version used in Paper IV

\begin{tabular}{|cl|}
\hline+2 & Goal achieved (much better than expected level of outcome) \\
\hline+1 & Goal achieved (better than expected level of outcome) \\
\hline 0 & Goal achieved (expected level of outcome) \\
\hline-1 & Goal not achieved (less than expected level of outcome) \\
\hline-2 & Goal not achieved (much less than expected level of outcome) - baseline \\
\hline
\end{tabular}

\section{Self-reported health related quality of life}

For HRQoL, we used the Short Form Health Survey (SF-36) instrument [186]. From the SF-36, we also had the option to calculate SF-6D for a health-economy evaluation. In addition the EQ-VAS [187] was used, where participants are asked to rate their current health on a vertical visual analogue scale, ranging from 0 (worst imaginable state) to 100 (perfect health).

\section{The participant's expectations}

It has been shown that expectations of a treatment may influence the perception of a successful outcome of the treatment [188]. Thus, the participants were asked about their expectations before treatment and the fulfilment of expectations after treatment [189]. At the end of the controlled phase, participants guessed which treatment period they thought was active treatment and their reason for thinking this. The goal of this procedure was to assess the effectiveness of the blinding procedure. 


\section{Cost-effectiveness analysis}

We had planned an analysis on cost-effectiveness, where the first controlled study only should have a health-care perspective and the open-phase study should have a societal perspective. As there were no change in HRQoL, this part of the study was not relevant. The protocol for this part can be seen on ClinicalTrial.gov (trial no:NCT02261142).

\section{Compliance and deviations}

The total time the assistive technology (AT) was used, for each 6-week treatment period, was registered electronically in the control unit. Deviations, continuously registered in a separate protocol if subjects contacted the study team, and in addition all participants were asked about any deviations at follow-ups. Adverse effects described in free text were subsequently categorised for analysis.

\subsubsection{Randomization and blinding}

Due to the small number of participants, a block randomization was used. Only the study coordinator knew to which group a specific participant belonged. Participants were informed that they would have two six-week periods, out of which one would not include electrical stimulation. Blinding was secured until the study protocols had been completed. Please refer to paper IV for a detailed description of the procedure for randomization and blinding.

\subsubsection{Intervention}

The intention in the study was to adhere to, as far as possible, the company's recommendation on use of the AT. Therefore, the interventions from the study team were minimal, only consisting of study related issues.

The AT consists of a two-piece garment and a control unit. The garment is equipped with 58 electrodes that enable individually set electrical stimulation of 42 separate groups of muscles (figure 12). The control unit is programmable, and the amplitude of the square pulses of current, at a frequency of $20 \mathrm{~Hz}$, is individually set for each muscle group based on an assessment of the spasticity pattern by therapists employed by the company, hereafter referred to as company therapist. 


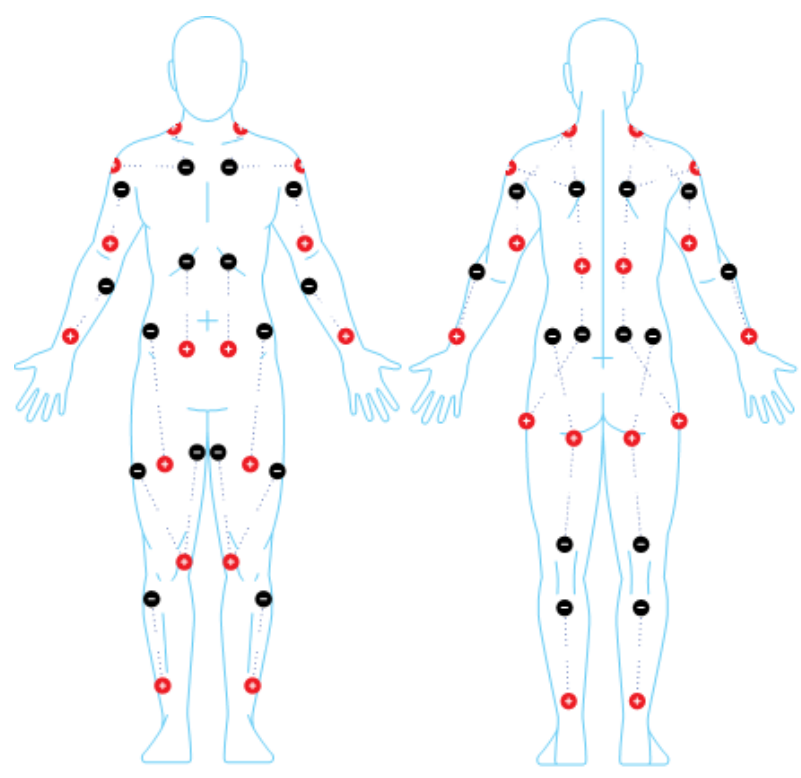

Figure 12: Electrode placement on the AT.

The use of the AT is possible in any dry location. In this study it was typically performed in the participants' home environment. The stimulation as such is said to be barely perceptible by the user, if at all. When using the AT, a timer on the control unit shows the remaining time of the pre-set 60 minutes of electrostimulation. The suggested training exercises while using the AT, were mainly training of strength, stretching and co-ordination.

To match the standard procedure used by the company, it was decided that company therapists did the initial patient assessment and programming of the control unit. A research therapist was present to ensure documentation of any deviations from the default procedure.

Participants were instructed to perform self-administered treatments in their home environment, i.e. to use the garment for 60 minutes, any suitable time of the day, three to four times a week. This should render 1,080 to 1,260 minutes of use, each six-week period. The control unit displayed remaining time of use, independently of whether the control unit gave any electrical stimulation. There were no study-related restrictions in participant's every-day life. Assessments took place at the hospital departments, at baseline and at the end of each six-week cycle, i.e. week 6, 12 and 18 from study start. Participants were informed to use the AT the day before assessment and not on assessment days. 


\subsubsection{Statistics}

Paired t-test was used to study outcomes with continuous variables. For non-parametric data, a paired-sample Wilcoxon signed-rank test was used. The analysis based on intention to treat (ITT) was including all participants. An ad hoc, per protocol (PP) analysis was performed to handle variations in compliance with the study protocol. To be included in the PP analysis, the participants had to have used the equipment for at least $2 / 3$ of the expected time in both treatment cycles. SPSS version 23 (SPSS Inc., Chicago, IL, USA) was used for all analyses.

\subsection{RESULtS}

Thirty-one participants were included, whereof 27 completed the study. Of the four participants discontinuing, two declined participation before baseline and two withdrew due to difficulties handling the garment. Of the participants completing the study, 12 had CP and 15 had stroke, 15 male and 12 female. In CP the GMFCS level was below 3 (median 2.5) and in stroke the mean NIHSS score was 5.4 (range 1-11).

Deviations and adverse events mainly consisted of technical problems with the garment and the control unit. Six out of the 27 patients reported pain, though the pain differed in its presentation and no systematic pattern was seen. All adverse advents reported are presented in Table 11.

Another major deviation was the use of the AT in relation to the protocol. The expected use was in the interval 1080 to 1260 minutes. In reality, the mean time the AT was used was 870 (range (48-1332) minutes, and only 6 out of the 27 participants used the AT for more than 1080 minutes in both treatment cycles. Fifteen participants fulfilled the inclusion for the PP analysis. Figure 13 presents the individual participants' time of AT use for both 6-weeks treatment cycles.

Table 11: Deviations and adverse effects reported during the study, divided according to the number of reports and the number of participants reporting adverse effects and deviations.

\begin{tabular}{|c|c|c|}
\hline Categories & $\begin{array}{l}\text { Number of } \\
\text { reported adverse } \\
\text { effects and } \\
\text { deviations }\end{array}$ & $\begin{array}{l}\text { Number of participants } \\
\text { reporting adverse } \\
\text { effects and deviations }\end{array}$ \\
\hline Pain $^{1}$ & 8 & 6 \\
\hline Technical problem - garment $t^{2}$ & 26 & 16 \\
\hline Technical problem - control unit ${ }^{3}$ & 23 & 17 \\
\hline Contact, logistical and/or comfort ${ }^{4}$ & 14 & 13 \\
\hline Increased need for assistance ${ }^{5}$ & 2 & 2 \\
\hline
\end{tabular}




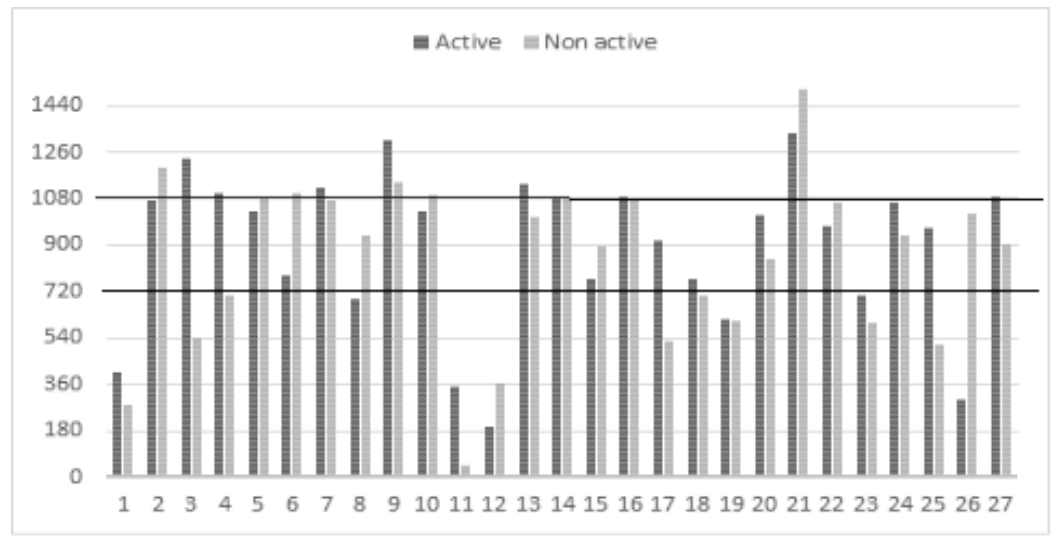

Figure 13: The use of the AT in minutes per six-week period, showing the active and nonactive period of each participant. The expected time if used according the protocol (above 1080 minutes) and the cut-off for the PP-analysis (720 minutes) are marked with horizontal lines.

For all 27 participants, the number of goals defined and evaluated according to GAS was 56. All goals were classified into ICF-codes, presented in paper IV, table 6 . The most frequent goals related to gait $(\mathrm{n}=25)$, with hand/arm related goals as second most common. Of the ICF codes, $64 \%$ were activity and participation related.

There were no differences between active and non-active treatment in any of the outcomes (tables 12 and 13). The T-score for goal attainment increased in both the active and the non-active period with no difference between the interventions, indicating that the individual goals set by each participant improved at group level (table 12).

There was a significant improvement in 10-meter comfortable gait test for the active period, but not in the non-active period. No changes were found in arm-hand ability, spasticity assessment, self-reported pain and spasticity measurements or in HRQoL instruments. Table 12, 13 and paper IV presents the results in more detail.

In the PP-analysis, the increase in T-score was only significant during the active treatment period. Otherwise, this ad-hoc analysis did not change the overall picture. 


\begin{tabular}{|c|c|c|c|c|c|c|c|c|c|c|}
\hline 啇 & 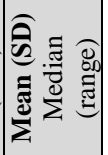 & 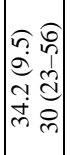 & 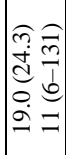 & 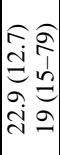 & 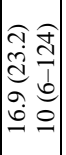 & 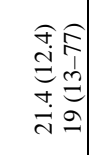 & 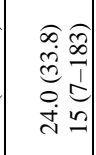 & $\begin{array}{ll}0 & 0 \\
0 & 0 \\
0 & 0 \\
6 & 0 \\
0 & 0 \\
0 & 0\end{array}$ & 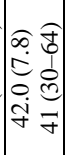 & 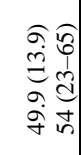 \\
\hline \multirow{2}{*}{ 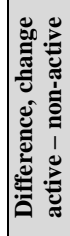 } & 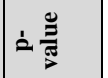 & $\frac{0}{6}$ & $\stackrel{n}{n}$ & $\begin{array}{l}\vec{n} \\
\text { ? }\end{array}$ & $\begin{array}{l}\tilde{n} \\
\text { fo }\end{array}$ & 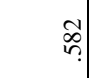 & ڤి & $\begin{array}{l}0 \\
b \\
\infty \\
\infty\end{array}$ & $\stackrel{0}{=}$ & 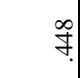 \\
\hline & 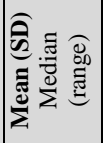 & 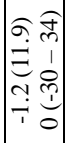 & 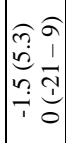 & 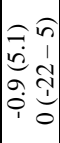 & $\mid \begin{array}{cc}0 & \widehat{A} \\
0 & 0 \\
0 & 1 \\
0 & \frac{1}{1} \\
- & 0\end{array}$ & 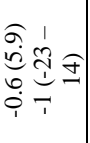 & 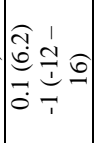 & 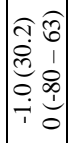 & 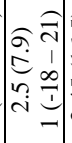 & 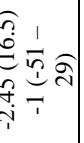 \\
\hline \multirow{2}{*}{ 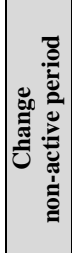 } & 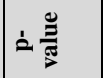 & $\stackrel{10}{\circ}$ & $\stackrel{2}{\stackrel{2}{ }}$ & $\stackrel{\infty}{\stackrel{\infty}{\uparrow}}$ & సి & 趸 & $\overrightarrow{\mathrm{N}}$ & 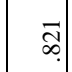 & है? & $\begin{array}{l}\text { \& } \\
\stackrel{f}{f}\end{array}$ \\
\hline & 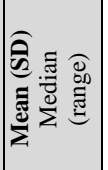 & 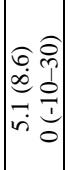 & 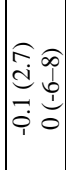 & 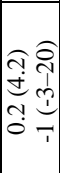 & 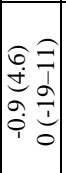 & 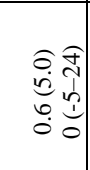 & 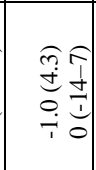 & 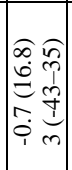 & 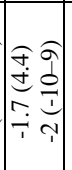 & 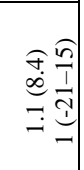 \\
\hline \multirow{2}{*}{ 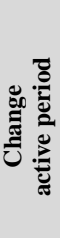 } & 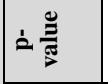 & อิ & $\stackrel{0}{\circ}$ & $\stackrel{f}{t}$ & $\begin{array}{c}\bar{\infty} \\
\infty\end{array}$ & $\stackrel{\infty}{\sigma}$ & $\exists$ & 志 & $\stackrel{\Xi}{\exists}$ & 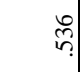 \\
\hline & 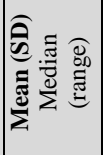 & 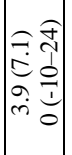 & 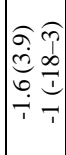 & 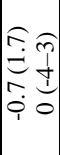 & 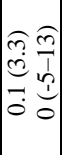 & 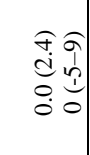 & 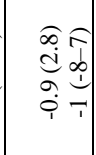 & 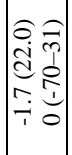 & 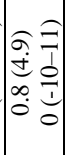 & 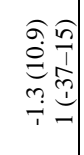 \\
\hline \multirow{2}{*}{ 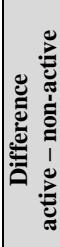 } & 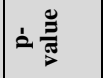 & $\begin{array}{r}\stackrel{0}{\infty} \\
\infty \\
0\end{array}$ & $\stackrel{ \pm}{I}$ & $\stackrel{\infty}{\stackrel{\sim}{?}}$ & $\begin{array}{l}0 \\
0 \\
0 \\
0\end{array}$ & ڤิ & $\underset{\substack{f \\
\infty}}{f}$ & $\stackrel{\infty}{\stackrel{\infty}{?}}$ & $\begin{array}{l}2 \\
\varnothing \\
0\end{array}$ & $\begin{array}{l}\text { त̦ } \\
\text { त̂t }\end{array}$ \\
\hline & 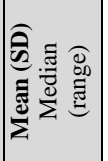 & 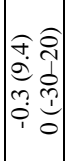 & $\begin{array}{cc}2 & 0 \\
\pm & 0 \\
- & 0 \\
-1 & 0\end{array}$ & 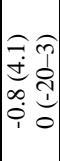 & 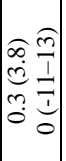 & 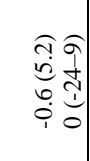 & 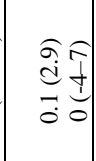 & 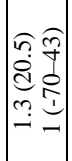 & 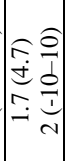 & 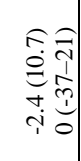 \\
\hline 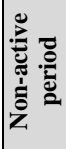 & 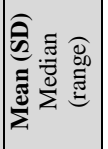 & 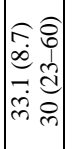 & 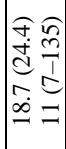 & 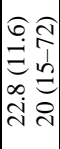 & 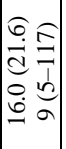 & 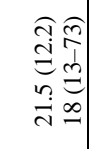 & 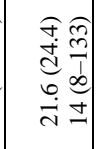 & 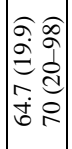 & 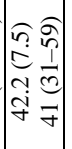 & $\begin{array}{cc}a & \hat{0} \\
0 & 0 \\
\infty & 0 \\
m & 0 \\
i n & 0 \\
n & n\end{array}$ \\
\hline 苞 & 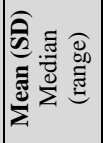 & 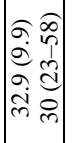 & 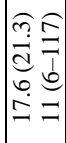 & 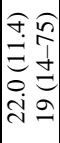 & 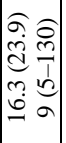 & 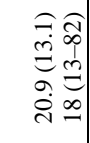 & 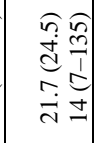 & $\begin{array}{ll}6 & 0 \\
\infty & 0 \\
= & 0 \\
- & 0 \\
0 & 0 \\
0 & 0\end{array}$ & 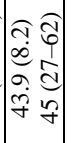 & 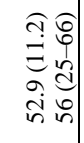 \\
\hline 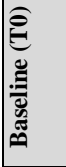 & 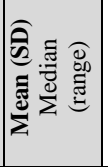 & 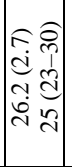 & 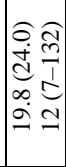 & 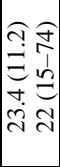 & 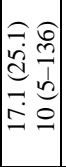 & 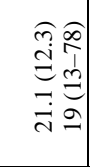 & 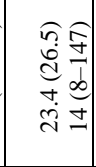 & 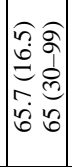 & 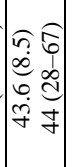 & 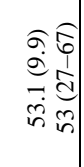 \\
\hline 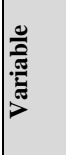 & & త్ర & 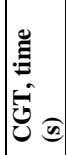 & 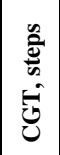 & 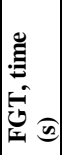 & 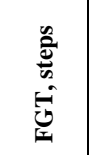 & 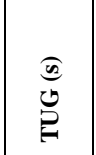 & 交 & 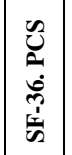 & 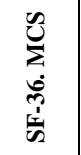 \\
\hline
\end{tabular}




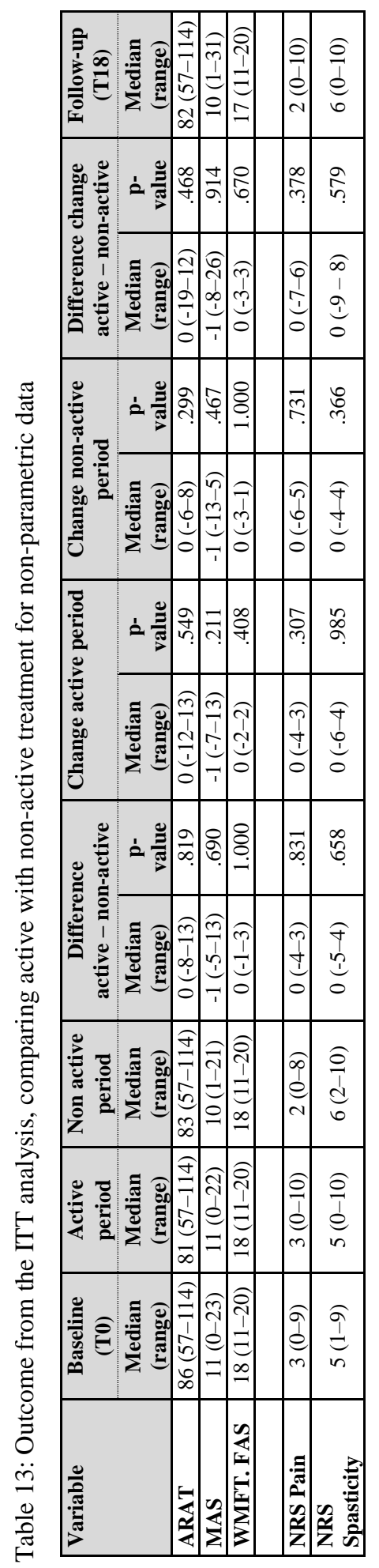




\subsection{Methodological discussion AND limitations}

In the design, the choice was to evaluate the commercial application of the AT, meaning that the study tried, not to optimize the effect, but mimic how the company offers the AT to potential customers. Being a double-blind RCT study, the interaction between the company therapist and the participants were restricted. This may have limited calibration and fine-tuning of the treatment, with a risk of sub-optimizing treatment effect. Two treatment periods of six weeks, without a washout period in between, might in retrospect have been too short to see an effect on activity and participation.

The study size was partly dependent on the number of available AT's, but was comparable to earlier RCT studies of TES on spasticity. The mixed study population, combined with the low compliance to treatment, may have decreased the power of the study, e.g. participants with CP had mostly normal or close to normal arm function, reducing the possibility to find changes in arm function tests.

Using a double-blind RCT design with assistive technology is challenging. Nineteen of 27 participants guessed correctly on what kind of treatment they had [190]. One possibility to reduce this problem would be to have two treatment arms and not a crossover design. This would have necessitated a much larger study, for which resources were not available.

This study differs in some aspects from earlier publications on TES for reducing spasticity [115, 171-177]:

Firstly, our intention was to evaluate a commercial product intended for use in the home without the need for therapist involvement in the daily treatment, in contrast to a more experimental design performed at a clinic.

Secondly, the AT in our study had a stimulation frequency of $20 \mathrm{~Hz}$ compared to previous studies where stimulation frequencies have varied from 20 to $200 \mathrm{~Hz}$ [191, 192], with $100 \mathrm{~Hz}$ being the most common frequency. Little is known about the optimal stimulation frequency with some evidence for spastic muscles needing higher frequencies for maximal reciprocal inhibition [193].

Thirdly, the training intensity has been rather low and less goal directed, compared with many other studies [172, 174, 176]. Recent studies of the importance of highintensity, goal-directed training suggests that this might be of importance for the outcome [194]. The blinding procedure in research on assistive technology is problematic and this study is the first investigating this factor in TES treatment for spasticity. 


\subsection{Conclusion}

No significant differences between the active and non-active intervention periods were found. The improvement observed in goal attainment, after both treatment periods in the main analysis, was only seen for the active period in the PP-analysis. As there was no difference in HRQoL, the health-economy evaluation could not be performed.

The absence of a clear result at group level does not rule out the possibility that certain individuals benefited from the intervention. This, supported by individual observations and participant reports, supports the need for further studies where observations from this study can aid in the design. 


\section{Discussion}

This thesis focuses on interventional aspects of spasticity, but has a very holistic approach, grounded in the specialty of Rehabilitation medicine. This means, capturing the effects of spasticity, on a complex biological system as the human being, living in a psychosocial context affecting the situation. It is here that the ICF aids us, as clinicians and researchers, in structuring the intricacy of capturing these aspects.

One obvious starting point is what we mean with spasticity. This has changed over the years and differs from most of the scientific literature compared with how clinical therapists, working with these patients, use the term. In this thesis, I advocate using spasticity as an umbrella term and subsequently defining the different components involved (figure 1). Thereby, we can avoid some of the confusion now existing. In light of the lack of consensus, it is of uttermost importance that scientific papers are explicit on the definition used. In paper III, this problem becomes apparent when trying to merge data on prevalence of spasticity in different diseases.

Evaluating spasticity in a consistent way is necessary for knowing what effect we get from our interventions. There are a number of levels on this, illustrated in figure 14. The first, of course, being that a treatment has the intended effect on the biological system, showing a treatment efficacy on spasticity reduction, e.g. showing that BoNT-A or a specific physical intervention can reduce a defined phenomenon of spasticity. This puts demands on the measurements to be highly reliable and with high precision. In measuring muscle tone, Ashworth scale might be insufficient for this purpose and Modified Tardieu being a better alternative as a clinical scale. For increased precision measures like EMG with or without mechanical components is probably a more exact alternative. A promising tool in this aspect is NeuroFlexor with a proposed ability to discriminate between neuromuscular and soft tissue components of the increased resistance to passive movement [195].

The second level is to evaluate if our treatment efforts improve movements, thus changing movements towards the normal and/or being performed with higher energy efficacy. For this, a very objective measure is needed for the studied movements, like gait laboratory analysis and Gait deviation Index. In paper II, we validated a new tool for movement analysis, with portable inertial sensors, more flexible and adaptive to different environments and probably with less cost per investigation compared to camera based systems.

The third level is to capture if this improvement in spasticity and movement patterns improves patients' ability to perform and participate in activities of daily life. At this level, we need instruments measuring the activities targeted for improvement. In the area of spasticity, this most often are improvement in gait or improvement of dexterity. Thus, we need different mobility tests and arm function tests. In paper IV, looking at efficacy of multifocal TES we did choose different reliable and valid instruments to measure this, and depending on the big variation in functioning among the participants 
there was a need to avoid instruments with too narrow measurement span, thus eluding floor and ceiling effects.

The fourth level, maybe being the ultimate challenge, is improving patient satisfaction. As life satisfaction is a multidimensional subjective appreciation of a person's situation, it is sometimes arguable if an isolated intervention will change this. Rather, we need a comprehensive multimodal rehabilitation, also approaching psychosocial factors. Instruments to capture this level are PROs. Generic HRQoL instruments are quite insensitive to change and therefore instruments with higher sensitivity are sometimes preferred, as GAS, COPM and condition-specific HRQoL instruments. In paper IV, GAS together with a generic HRQoL instrument (SF-36) was used, with the intention of both having a high sensitivity for change and a possibility for comparing results between conditions.

The fifth level is the societal level. That is, even if we can show that a treatment is efficient in treating a problem; is this effect big enough compared to the cost, to justify its use? To study this we need health-economic studies that put the cost in relation to the health gain. Ideally, a health-economic study is performed alongside a prospective RCT study, thereby having control over the methodology and the factors involved. This approach was used in paper IV. Another approach in health-economics is using already existing data, from publications and public data, for the analysis. This approach was used in paper III.

As the population grows older and the health systems in most countries are underfinanced (at least according to health personnel), the need to prioritize among our interventions becomes more important. Health economic evaluations are the necessary tool for this process, not least when added to conventional RCT studies. In the field of spasticity, there are too few such studies, and future research ought to put a bigger emphasis on this scientific field. 


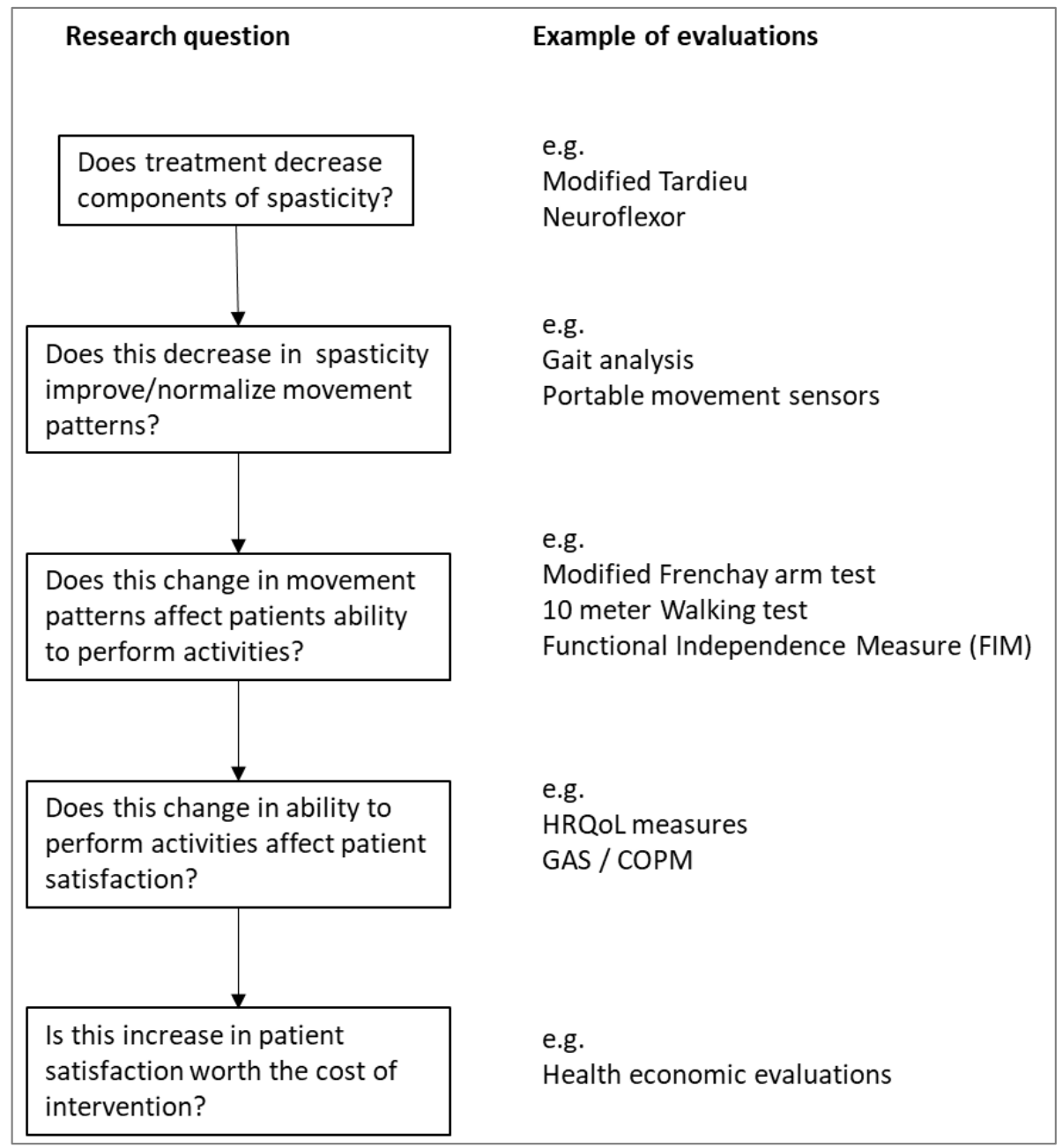

Figure 14: Hierarchy of research question in spasticity and examples of instruments to answer the question. 


\section{CONCLUSIONS AND IMPLICATIONS FOR FURTHER RESEARCH}

In this thesis, I have had the privilege to explore different methods of evaluating spasticity interventions from a multimodal perspective and it is only the starting point in an effort to understand more of this intriguing phenomenon.

Spasticity is still a major problem for many of our patients with an injury to the CNS and we need to develop our treatments in order to increase efficacy. There are no obvious new miracle drugs on the horizon, and instead we need further refinement of our existing tools, which has been the focus of this thesis. As a conclusion of this thesis, we may revisit the three main aims that were formulated and directed the content:

\section{How can we optimally evaluate spasticity management from the perspective of functioning?}

Paper I on Goal Attainment Scaling showed this instrument to be sensitive for capturing the patient perspective on functioning, most often on activity and participation. The paper also pointed out necessary aspects to consider when using this instrument. This comprises in particular the need of learning ("the art of") goal setting and beforehand deciding the purpose of the measurements. Furthermore, for clinical use, the paper reports recent efforts to simplify the use of GAS, with particular reference to the papers emerging from Turner Stokes' research [70, 83, 173-177]. For research, the paper points out the importance of also to be able to register deterioration, where one alternative is using the 6-step version.

Further, in Paper II the use of a novel method with portable inertial sensors to calculate motion parameters and graphically illustrate movement patterns was evaluated. This method was able, qualitatively and quantitatively, to evaluate arm function in activity, thus adding further precision to the evaluation of functioning. However, the equipment needs further development in handling long-term measurements, and norms for normal movements in different activities has to be defined. The use of EVA was promising, but its discriminative value needs confirmation. Additionally, the equipment has to improve its user-friendliness before broader implementation is feasible. For the future, there are the intriguing possibility of long-term measurements in patients' every-day life, thereby getting objective measures on how our patients use their abilities, thus capturing the difference between what you can do and what you actually do.

In paper IV, adopting a holistic approach, including all levels of ICF, for measuring spasticity and its consequences on functioning, this strategy was shown to be feasible. This study is an example of how evaluation of interventions can be optimized by considering the concept of functioning in assessment of different perspectives, including GAS and HRQoL. Thereby, not only capturing the effects on body function, but also the consequences and the suffering of the patient. 


\section{Is therapeutic electrical stimulation for treatment of spasticity an effective and}

feasible method?

The aspect of evaluation and the rationale for choosing a broad assessment approach has just been discussed, as it pertains to paper IV. When focusing on the specific intervention method under study, the results could not confirm efficacy with the treatment. However, the results should be interpreted with care, as low compliance and frequent adverse events made deduction difficult. Individual patient anecdotes, from the study, implicate that there is an effect not captured in the RCT. Further studies are needed in a number of areas, e.g. what is the optimal stimulation frequency, what patients can gain from the treatment and how should adjunct treatment be organized.

\section{How can health economic analysis, fruitfully, be applied to the evaluation of spasticity management?}

The results from paper III demonstrated a large inequality in Sweden regarding the accessibility for BoNT-A treatment for spasticity. We could also show that treatment with BoNT-A is sound from a health-economic perspective, accounting for the uncertainty of data via the sensitivity analysis. For the future, we need to explore if this inequality also exists for other modes of spasticity treatments, e.g. multidisciplinary spasticity treatment and ITB pumps, and in other countries.

In paper IV, we planned a health-economic study alongside the RCT. However, as efficacy data did not show any difference between active and non-active treatment, a health-economic evaluation became meaningless. In this situation, from a healtheconomic perspective, only cost savings can justify the use of the treatment, which was not the case.

Some of the research questions above are already in the "pipeline" for coming studies, other are to be planned by our research groups or others. 


\section{ACKNOWLEDGEMENTS}

So many people have been important for me being here today. Of course all research associates, but also family and friends. Here I will limit myself to those being of primary significance for the completion of this thesis.

My dear friend and principal supervisor, Professor Richard Levi. Thank you for your support, patience and linguistic skills. Your scientific expertise have been invaluable in bringing the four papers together; thus having one coherent story told. It has been a pleasure to have you on board these last years. I have enjoyed our cooperation, even though I enjoy our philosophical discussions even more.

Björn Gerdle was my principal supervisor the first years of my research and have always been encouraging regarding research. You have been immensely important for the scientific development of Rehabilitation Medicine in Linköping.

Helena Grip, you came in as my assistant supervisor in the project on portable sensors. Your knowledge in the field of technology and statistics is so impressing and invaluable. Now as this thesis is over, I am looking forward to our coming projects.

Wolfram Antepohl, head of the clinical department of Rehabilitation Medicine. I thank you for allowing me the necessary time to be able to finish this dissertation and I hope that we can continue our joint struggle to develop the scientific field within neurological rehabilitation in Linköping.

Jenny Alwin, my mentor within the field of health-economics. Always with a big smile on her face and enthusiastically taking part in discussions on study design and how health-economy analysis could be part of it. In this, you have been my informal assistant supervisor.

My co-researchers in paper I, being Anthony Ward, Jörg Wissel and Jörgen Borg. Three professors from three different countries, also being the lead researchers for the BEST study, who have generously shared their scientific experience. I have learnt a lot about research, not least the difficulties in performing a multicenter RCT.

My co-researchers in paper II, being Fredrik Öhberg Björn Gerdle and Helena Grip. It has been a privilege to work with you in Paper II, as well as now in planning for coming studies on the portable movement system.

My co-researchers in paper III, Annabelle Forsmark and Mats Anhammer. The project started as a loose discussion on what differences there are in spasticity care. From there the questions piled up and the project became alive. Now I look forward to our continued work with the follow-up study.

Annabelle Forsmark is the second health-economist trying to make me understand at least something, hopefully not in total vain.

My co-researchers in paper IV, Jenny Alwin, Ann Sörbo, Marie Lindgren and Leif Sandsjö. We have been a very good group, sharing joy and frustrations during the process. I am very glad to have you as friends and co-workers.

Kersti Samuelsson, occupational therapist and assistant professor at the department of Rehabilitation Medicine. You had to, under a number of years, carry the scientific ambitions on your own shoulders, which you did in an eminent way. The result we see today with an increasing number of publications "popping out" from the department. It has been a pleasure to work with you both in research, clinical work and in the management of the department of Rehabilitation Medicine during the first decennium of the millennium. 
The spasticity team, with nurses Ulla Bengtsson, Madeleine Wickström, Emelie Tjärnliden, SofieLovis Obermeier and Stina Gunnarsson as well as occupational therapist Birgitta Rustner and physiotherapists Marie Lannesand and Eva Härkegård. You are a fabulous group of people and without your help and patience; I would never have been able to fulfil this dissertation.

The pediatric rehabilitation team consisting of Ragni Gunnarsson, Karin Erklint, Katarina Svensson, Josefin Larsson, Linda Everborn, Erika Jensen and Helen Sundelin. You have not been part of these projects but have suffered from my lack of time in the clinic. When I have felt tired, I have been able to pass by just to get energy from your positive "chakra" :-).

Professor Lennart Levi and his late wife Isabella who with their inclusiveness during my childhood made me understand that being a doctor was a career alternative.

My friend Christer Ekdahl who agreed to be toastmaster for this happening, but most of all are occupied with making me realize that work and research not is the most important part of life.

My parents Aslaug and Jon Henrik who always have been by my side since childhood, and accepting me for being me, although my mother always thought that I could dress a little better. You have worked hard raising three children, apart from me also Stein and Karen and I am very happy that all of you are still with me, both in body and spirit.

Linn and Oskar. My two beloved children of whom I am immensely proud. Raising you is for sure, my greatest accomplishment throughout my life, and one of the rewards is my grandson Neo, having me realize with what to spend my time when I retire.

My beloved Erika and her children Nils and Ingrid. I am so grateful for all your support during this period of writing, when I have been in my "bubble", barely contactable. Though, most of all I am grateful for you being you. Love you! 


\section{REFERENCES}

1. Lorentzen, J., et al., On Denny-Brown's 'spastic dystonia' - What is it and what causes it? Clin Neurophysiol, 2018. 129(1): p. 89-94.

2. Dressler, D., et al., Defining spasticity: a new approach considering current movement disorders terminology and botulinum toxin therapy. J Neurol, 2018. 265(4): p. 856-862.

3. Lance, J.W., Symposium synopsis, in Spasticity: disorder of motor control. , R.G. Feldman, R.R. Young, and W.P. Koella, Editors. 1980: Chicago. p. 485-94.

4. Pandyan, A.D., et al., Spasticity: Clinical perceptions, neurological realities and meaningful measurement. Disability \& Rehabilitation, 2005. 27(1-2): p. 2-6.

5. Gracies, J.M., et al., Five-step clinical assessment in spastic paresis. Eur J Phys Rehabil Med, 2010. 46(3): p. 411-21.

6. Burns, A.S., et al., Optimizing the Management of Disabling Spasticity Following Spinal Cord Damage: The Ability Network-An International Initiative. Arch Phys Med Rehabil, 2016. 97(12): p. 2222-2228.

7. Urban, P.P., et al., Occurence and clinical predictors of spasticity after ischemic stroke. Stroke, 2010. 41(9): p. 2016-20.

8. Opheim, A., et al., Upper-limb spasticity during the first year after stroke: stroke arm longitudinal study at the University of Gothenburg. Am J Phys Med Rehabil, 2014. 93(10): p. 884-96.

9. Sunnerhagen, K.S., A. Opheim, and M. Alt Murphy, Onset, time course and prediction of spasticity after stroke or traumatic brain injury. Ann Phys Rehabil Med, 2018.

10. Wissel, J., et al., Early development of spasticity following stroke: a prospective, observational trial. J Neurol, 2010. 257(7): p. 1067-72.

11. Verplancke, D., et al., A randomized controlled trial of botulinum toxin on lower limb spasticity following acute acquired severe brain injury. Clinical Rehabilitation, 2005. 19(2): p. 117-125.

12. Li, S., Spasticity, Motor Recovery, and Neural Plasticity after Stroke. Front Neurol, 2017. 8: p. 120.

13. Burke, D., J. Wissel, and G.A. Donnan, Pathophysiology of spasticity in stroke. Neurology, 2013. 80(3 Suppl 2): p. S20-6.

14. Vinti, M., et al., Muscle Shortening and Spastic Cocontraction in Gastrocnemius Medialis and Peroneus Longus in Very Young Hemiparetic Children. Biomed Res Int, 2018. 2018: p. 2328601.

15. Trompetto, C., et al., Pathophysiology of spasticity: implications for neurorehabilitation. Biomed Res Int, 2014. 2014: p. 354906.

16. James, S.E.F.M., Contractures in orthopaedic and neurological conditions: a review of causes and treatment. Disability and Rehabilitation, 2009. 23(13): p. 549-558.

17. Spasticity: Diagnosis and Management, ed. E. Elovic and A. Brashear. 2011, New York: Demos Medical publishing, LLC.

18. Mukherjee, A. and A. Chakravarty, Spasticity mechanisms - for the clinician. Front Neurol, 2010. 1: p. 149.

19. Li, S. and G.E. Francisco, New insights into the pathophysiology of post-stroke spasticity. Front Hum Neurosci, 2015. 9: p. 192.

20. Wissel, J., A. Manack, and M. Brainin, Toward an epidemiology of poststroke spasticity. Neurology, 2013. 80(3 Suppl 2): p. S13-9.

21. Shin, Y.I., et al., Association Between Spasticity and Functional Impairments During the First Year After Stroke in Korea: The KOSCO Study. Am J Phys Med Rehabil, 2018. 97(8): p. 557564. 
22. Dornak, T., et al., Early manifestation of spasticity after first stroke in the territory of the internal carotid artery: A prospective multicenter study. Biomed Pap Med Fac Univ Palacky Olomouc Czech Repub, 2018.

23. Ehrmann, C., et al., Describing Functioning in People Living With Spinal Cord Injury in Switzerland: A Graphical Modeling Approach. Arch Phys Med Rehabil, 2018.

24. Skold, C., R. Levi, and A. Seiger, Spasticity after traumatic spinal cord injury: nature, severity, and location. Arch Phys Med Rehabil, 1999. 80(12): p. 1548-57.

25. Ahlgren, C., A. Oden, and J. Lycke, High nationwide prevalence of multiple sclerosis in Sweden. Mult Scler, 2011. 17(8): p. 901-8.

26. Himmelmann, K. and P. Uvebrant, The panorama of cerebral palsy in Sweden part XII shows that patterns changed in the birth years 2007-2010. Acta Paediatr, 2018. 107(3): p. 462-468.

27. Ertzgaard, P., M. Anhammer, and A. Forsmark, Regional disparities in botulinum toxin $A$ (BoNT-A) therapy for spasticity in Sweden: budgetary consequences of closing the estimated treatment gap. Acta Neurol Scand, 2017. 135(3): p. 366-372.

28. Westgren, N. and R. Levi, Quality of life and traumatic spinal cord injury. Arch Phys Med Rehabil, 1998. 79(11): p. 1433-9.

29. Geyh, S., et al., Describing functioning and health after spinal cord injury in the light of psychological-personal factors. J Rehabil Med, 2016. 48(2): p. 219-34.

30. Zwibel, H.L. and J. Smrtka, Improving quality of life in multiple sclerosis: an unmet need. Am J Manag Care, 2011. 17 Suppl 5 Improving: p. S139-45.

31. Lobentanz, I.S., et al., Factors influencing quality of life in multiple sclerosis patients: disability, depressive mood, fatigue and sleep quality. Acta Neurol Scand, 2004. 110(1): p. 613.

32. Katona, M., et al., Predictors of health-related quality of life in stroke patients after neurological inpatient rehabilitation: a prospective study. Health Qual Life Outcomes, 2015. 13: p. 58.

33. Lynch, E.B., et al., A qualitative study of quality of life after stroke: the importance of social relationships. J Rehabil Med, 2008. 40(7): p. 518-23.

34. Dijkers, M.P., Quality of life after traumatic brain injury: a review of research approaches and findings. Arch Phys Med Rehabil, 2004. 85(4 Suppl 2): p. S21-35.

35. Lundstrom, E., et al., Four-fold increase in direct costs of stroke survivors with spasticity compared with stroke survivors without spasticity: the first year after the event. Stroke, 2010. 41(2): p. 319-24.

36. Arroyo, R., M. Massana, and C. Vila, Correlation between spasticity and quality of life in patients with multiple sclerosis: the CANDLE study. Int J Neurosci, 2013. 123(12): p. 850-8.

37. Flachenecker, P., T. Henze, and U.K. Zettl, Spasticity in patients with multiple sclerosis-clinical characteristics, treatment and quality of life. Acta Neurol Scand, 2014. 129(3): p. 15462.

38. Adriaansen, J.J., et al., Secondary health conditions and quality of life in persons living with spinal cord injury for at least ten years. J Rehabil Med, 2016. 48(10): p. 853-860.

39. Gillard, P.J., et al., The negative impact of spasticity on the health-related quality of life of stroke survivors: a longitudinal cohort study. Health Qual Life Outcomes, 2015. 13: p. 159.

40. Westerkam, D., L.L. Saunders, and J.S. Krause, Association of spasticity and life satisfaction after spinal cord injury. Spinal Cord, 2011. 49(9): p. 990-4.

41. Doan, Q.V., et al., Relationship between disability and health-related quality of life and caregiver burden in patients with upper limb poststroke spasticity. PM R, 2012. 4(1): p. 4-10.

42. Zorowitz, R.D., P.J. Gillard, and M. Brainin, Poststroke spasticity: sequelae and burden on stroke survivors and caregivers. Neurology, 2013. 80(3 Suppl 2): p. S45-52.

43. Clark, P.C., et al., Potential benefits for caregivers of stroke survivors receiving BTX-A and exercise for upper extremity spasticity. Rehabil Nurs, 2015. 40(3): p. 188-96. 
44. Denno, M.S., et al., Anxiety and depression associated with caregiver burden in caregivers of stroke survivors with spasticity. Arch Phys Med Rehabil, 2013. 94(9): p. 1731-6.

45. Nam, H.S., et al., Efficacy and safety of NABOTA in post-stroke upper limb spasticity: a phase 3 multicenter, double-blinded, randomized controlled trial. J Neurol Sci, 2015. 357(1-2): p. 192-7.

46. Lam, K., et al., Can botulinum toxin decrease carer burden in long term care residents with upper limb spasticity? A randomized controlled study. J Am Med Dir Assoc, 2012. 13(5): p. 477-84.

47. Stevenson, V.L., et al., The high cost of spasticity in multiple sclerosis to individuals and society. Mult Scler, 2015. 21(12): p. 1583-92.

48. Ganapathy, V., et al., Caregiver burden, productivity loss, and indirect costs associated with caring for patients with poststroke spasticity. Clin Interv Aging, 2015. 10: p. 1793-802.

49. Vidal, J., et al., Cost-effectiveness of Intrathecal Baclofen Therapy in severe refractory nonfocal disabling spasticity: a Spanish hospital perspective. Expert Rev Pharmacoecon Outcomes Res, 2016: p. 1-10.

50. Rychlik, R., et al., Quality of life and costs of spasticity treatment in German stroke patients. Health Econ Rev, 2016. 6(1): p. 27.

51. Doan, Q.V., et al., Cost-effectiveness of onabotulinumtoxinA for the treatment of wrist and hand disability due to upper-limb post-stroke spasticity in Scotland. Eur I Neurol, 2013. 20(5): p. 773-80.

52. World Health Organization., ICF: International classification of functioning, disability and health. 2001, WHO: Geneva.

53. Thyberg, M., et al., Simplified bipartite concepts of functioning and disability recommended for interdisciplinary use of the ICF. Disabil Rehabil, 2015. 37(19): p. 1783-92.

54. WHO. Classifications. 2018; Available from: http://www.who.int/classifications/icd/en/.

55. Cieza, A., et al., Towards a minimal generic set of domains of functioning and health. BMC Public Health, 2014. 14: p. 218.

56. Prodinger, B., et al., Toward the International Classification of Functioning, Disability and Health (ICF) Rehabilitation Set: A Minimal Generic Set of Domains for Rehabilitation as a Health Strategy. Arch Phys Med Rehabil, 2016. 97(6): p. 875-84.

57. Cieza, A., et al., ICF linking rules: an update based on lessons learned. J Rehabil Med, 2005. 37(4): p. 212-8.

58. Ertzgaard, P., C. Kiekens, and A.V. Nene, Patient-relevant outcome measures for spasticity in $S C I$ for research and clinical practice. Recommendations from the ABILITY Network Outcomes and Access Working Group. in manuscript, 2017.

59. Farin, E., A. Fleitz, and C. Frey, Psychometric properties of an International Classification of Functioning, Disability and Health (ICF)-oriented, adaptive questionnaire for the assessment of mobility, self-care and domestic life. J Rehabil Med, 2007. 39(7): p. 537-46.

60. Nene, A.V., et al., Clinical Assessment of Spasticity in People With Spinal Cord Damage: Recommendations From the Ability Network, an International Initiative. Arch Phys Med Rehabil, 2018.

61. Aloraini, S.M., et al., Assessment of spasticity after stroke using clinical measures: a systematic review. Disabil Rehabil, 2015. 37(25): p. 2313-23.

62. Basch, E., New frontiers in patient-reported outcomes: adverse event reporting, comparative effectiveness, and quality assessment. Annu Rev Med, 2014. 65: p. 307-17.

63. Carswell, A., et al., The Canadian Occupational Performance Measure: a research and clinical literature review. Can J Occup Ther, 2004. 71(4): p. 210-22.

64. Kiresuk, T. and R.E. Sherman, Goal attainment scaling: a general method for evaluating comprehensive community mental health programs. Commun Ment Health J, 1968. 4: p. 443-53. 
65. Ruble, L., J.H. McGrew, and M.D. Toland, Goal attainment scaling as an outcome measure in randomized controlled trials of psychosocial interventions in autism. J Autism Dev Disord, 2012. 42(9): p. 1974-83.

66. Fisher, K., Assessing clinically meaningful change following a programme for managing chronic pain. Clin Rehabil, 2008. 22(3): p. 252-9.

67. Fisher, K. and R.J. Hardie, Goal attainment scaling in evaluating a multidisciplinary pain management programme. Clinical Rehabilitation, 2002. 16(8): p. 871-877.

68. Grant, M., J. Ponsford, and P.C. Bennett, The application of Goal Management Training to aspects of financial management in individuals with traumatic brain injury. Neuropsychol Rehabil, 2012. 22(6): p. 852-73.

69. King, G.A., et al., Goal Attainment Scaling: its use in evaluating pediatric therapy programs. Phys Occup Ther Pediatr, 2000. 19: p. 31-52.

70. Wallen, M., et al., Modified constraint-induced therapy for children with hemiplegic cerebral palsy: a randomized trial. Dev Med Child Neurol, 2011. 53(12): p. 1091-9.

71. Steenbeek, D., et al., Responsiveness of Goal Attainment Scaling in comparison to two standardized measures in outcome evaluation of children with cerebral palsy. Clin Rehabil, 2011. 25(12): p. 1128-39.

72. Ward, A.B., et al., Functional goal achievement in post-stroke spasticity patients: the BOTOX(R) Economic Spasticity Trial (BEST). J Rehabil Med, 2014. 46(6): p. 504-13.

73. Turner-Stokes, L., et al., Upper limb international spasticity study: rationale and protocol for a large, international, multicentre prospective cohort study investigating management and goal attainment following treatment with botulinum toxin A in real-life clinical practice. BMJ Open, 2013. 3(3).

74. Stolee, P., et al., A multi-site study of the feasibility and clinical utility of Goal Attainment Scaling in geriatric day hospitals. Disabil Rehabil, 2012. 34(20): p. 1716-26.

75. Kiresuk, T., A. Smith, and J. Cardillo, Goal Attainment Scaling: Applications, Theory, and Measurement. 1994, New York: Lawrence Erlbaum Associates.

76. Bovend'Eerdt, T.J., R.E. Botell, and D.T. Wade, Writing SMART rehabilitation goals and achieving goal attainment scaling: a practical guide. Clin Rehabil, 2009. 23(4): p. 352-61.

77. Ertzgaard, P., et al., Practical considerations for goal attainment scaling during rehabilitation following acquired brain injury. J Rehabil Med, 2011. 43(1): p. 8-14.

78. Sakzewski, L., R. Boyd, and J. Ziviani, Clinimetric properties of participation measures for 5- to 13-year-old children with cerebral palsy: a systematic review. Dev Med Child Neurol, 2007. 49(3): p. 232-40.

79. Grant, M. and J. Ponsford, Goal Attainment Scaling in brain injury rehabilitation: Strengths, limitations and recommendations for future applications. Neuropsychol Rehabil, 2014: p. 117.

80. King, G.A., et al., An Evaluation of Functional, School-Based Therapy Services for Children with Special Needs. Physical \& Occupational Therapy in Pediatrics, 1999. 19(2): p. 5-29.

81. Ashford, S. and L. Turner-Stokes, Goal Attainment Scaling in Adult Neurorehabilitation, in Rehabilitation goal setting : theory, practice and evidence, R.S. Siegert and W. Levack, Editors. 2015, CRC Press: Boca Raton. p. 123-42.

82. WHO. International Classification of Functioning, Disability and Health (ICF). 201710 January 2014 [cited 201730 june]; Available from: http://www.who.int/classifications/icf/en/.

83. Bouwens, S.F., C.M. van Heugten, and F.R. Verhey, The practical use of goal attainment scaling for people with acquired brain injury who receive cognitive rehabilitation. Clin Rehabil, 2009. 23(4): p. 310-20.

84. Turner-Stokes, L., H. Williams, and J. Johnson, Goal attainment scaling: does it provide added value as a person-centred measure for evaluation of outcome in neurorehabilitation following acquired brain injury? J Rehabil Med, 2009. 41(7): p. 528-35. 
85. Gordon, J.E., C. Powell, and K. Rockwood, Goal attainment scaling as a measure of clinically important change in nursing-home patients. . Age and Ageing, 1999. 28: p. 275-81.

86. Rockwood, K., et al., Responsiveness of goal attainment scaling in a randomized controlled trial of comprehensive geriatric assessment. Journal of Clinical Epidemiology, 2003. 56(8): p. 736-743.

87. Malec, J.F., Goal Attainment Scaling in Rehabilitation. Neuropsychol Rehabil Psychol, 1999. 9: p. 253-75.

88. Joyce, B.M., K.J. Rockwood, and C.C. Mate-Kole, Use of goal attainment scaling in brain injury in a rehabilitation hospital. Am J Phys Med Rehabil, 1994. 73(1): p. 10-4.

89. Lannin, N., Goal attainment scaling allows program evaluation of a home-based occupational therapy program. Occup Ther Health Care, 2003. 17(1): p. 43-54.

90. Rockwood, K., B. Joyce, and P. Stolee, Use of goal attainment scaling in measuring clinically important change in cognitive rehabilitation patients. J Clin Epidemiol, 1997. 50: p. 581-8.

91. Rockwood, K., B. Joyce, and P. Stolee, Use of goal attainment scaling in measuring clinically important change in cognitive rehabilitation patients. J Clin Epidemiol, 1997. 50(5): p. 581-8.

92. Brown, D.A., S.K. Effgen, and R.J. Palisano, Performance following ability-focused physical therapy intervention in individuals with severely limited physical and cognitive abilities. Phys Ther, 1998. 78(9): p. 934-47; discussion 948-50.

93. Steenbeek, D., et al., Interrater reliability of goal attainment scaling in rehabilitation of children with cerebral palsy. Arch Phys Med Rehabil, 2010. 91(3): p. 429-35.

94. Vu, M. and A.V. Law, Goal-attainment scaling: a review and applications to pharmacy practice. Res Social Adm Pharm, 2012. 8(2): p. 102-21.

95. Fheodoroff, K., et al., Factors influencing goal attainment in patients with post-stroke upper limb spasticity following treatment with botulinum toxin A in real-life clinical practice: subanalyses from the Upper Limb International Spasticity (ULIS)-II Study. Toxins (Basel), 2015. 7(4): p. 1192-205.

96. Hurn, J., I. Kneebone, and M. Cropley, Goal setting as an outcome measure: A systematic review. Clin Rehabil, 2006. 20(9): p. 756-72.

97. Lowing, K., et al., Exploring the relationship of family goals and scores on standardized measures in children with cerebral palsy, using the ICF-CY. Dev Neurorehabil, 2011. 14(2): p. 79-86.

98. Cheung, J., et al., Patient-identified factors that influence spasticity in people with stroke and multiple sclerosis receiving botulinum toxin injection treatments. Physiother Can, 2015. 67(2): p. 157-66.

99. Lanig, I.S., et al., Optimizing the Management of Spasticity in People With Spinal Cord Damage: A Clinical Care Pathway for Assessment and Treatment Decision Making From the Ability Network, an International Initiative. Arch Phys Med Rehabil, 2018.

100. Sommerfeld, D.K., U. Gripenstedt, and A.K. Welmer, Spasticity after stroke: an overview of prevalence, test instruments, and treatments. Am J Phys Med Rehabil, 2012. 91(9): p. 81420.

101. Amatya, B., et al., Non pharmacological interventions for spasticity in multiple sclerosis. Cochrane Database Syst Rev, 2013. 2(2): p. CD009974.

102. Sirtori, V., et al., Constraint-induced movement therapy for upper extremities in stroke patients. Cochrane Database Syst Rev, 2009(4): p. CD004433.

103. Katalinic, O.M., L.A. Harvey, and R.D. Herbert, Effectiveness of stretch for the treatment and prevention of contractures in people with neurological conditions: a systematic review. Phys Ther, 2011. 91(1): p. 11-24.

104. Harvey, L.A., et al., Stretch for the treatment and prevention of contractures. Cochrane Database Syst Rev, 2017. 1: p. CD007455.

105. Roche, N., et al., Effect of rehabilitation and botulinum toxin injection on gait in chronic stroke patients: a randomized controlled study. J Rehabil Med, 2015. 47(1): p. 31-7. 
106. Pradines, M., et al., Effect on Passive Range of Motion and Functional Correlates After a Long-Term Lower Limb Self-Stretch Program in Patients With Chronic Spastic Paresis. PM R, 2018.

107. Marsal, C., et al., Beliefs of rehabilitation professionals towards guided self-rehabilitation contracts for post stroke hemiparesis. Top Stroke Rehabil, 2017. 24(8): p. 608-613.

108. Flinn, S.R. and K. Craven, Upper limb casting in stroke rehabilitation: rationale, options, and techniques. Top Stroke Rehabil, 2014. 21(4): p. 296-302.

109. Newman, M. and K. Barker, The effect of supported standing in adults with upper motor neurone disorders: a systematic review. Clin Rehabil, 2012. 26(12): p. 1059-77.

110. Synnot, A., et al., Interventions for managing skeletal muscle spasticity following traumatic brain injury. Cochrane Database Syst Rev, 2017. 11: p. CD008929.

111. Alfieri, V., Electrical treatment of spasticity. Reflex tonic activity in hemiplegic patients and selected specific electrostimulation. Scand J Rehabil Med, 1982. 14(4): p. 177-82.

112. Schuhfried, O., et al., Non-invasive neuromuscular electrical stimulation in patients with central nervous system lesions: an educational review. J Rehabil Med, 2012. 44(2): p. 99-105.

113. Bosques, G., et al., Does therapeutic electrical stimulation improve function in children with disabilities? A comprehensive literature review. J Pediatr Rehabil Med, 2016. 9(2): p. 83-99.

114. Tinazzi, M., et al., Long-lasting modulation of human motor cortex following prolonged transcutaneous electrical nerve stimulation (TENS) of forearm muscles: evidence of reciprocal inhibition and facilitation. Exp Brain Res, 2005. 161(4): p. 457-64.

115. Mills, P.B. and F. Dossa, Transcutaneous Electrical Nerve Stimulation for Management of Limb Spasticity: A Systematic Review. Am J Phys Med Rehabil, 2016. 95(4): p. 309-18.

116. Chan, K.S., et al., Effects of a single session of whole body vibration on ankle plantarflexion spasticity and gait performance in patients with chronic stroke: a randomized controlled trial. Clin Rehabil, 2012. 26(12): p. 1087-95.

117. Pang, M.Y.C., R.W.K. Lau, and S.P. Yip, The effects of whole-body vibration therapy on bone turnover, muscle strength, motor function, and spasticity in chronic stroke: a randomized controlled trial Eur J Phys Rehabil Med, 2013. 49(4): p. 439-50.

118. Katusic, A., S. Alimovic, and V. Mejaski-Bosnjak, The effect of vibration therapy on spasticity and motor function in children with cerebral palsy: a randomized controlled trial. NeuroRehabilitation, 2013. 32(1): p. 1-8.

119. Naro, A., et al., Breakthroughs in the spasticity management: Are non-pharmacological treatments the future? J Clin Neurosci, 2017. 39: p. 16-27.

120. Thibaut, A., et al., Spasticity after stroke: physiology, assessment and treatment. Brain Inj, 2013. 27(10): p. 1093-105.

121. Shakespeare, D., M. Boggild, and C.A. Young, Anti-spasticity agents for multiple sclerosis. The cochrane collaboration, 2009(1).

122. Taricco, M., et al., Pharmacological interventions for spasticity following spinal cord injury. Cochrane Database Syst Rev, 2000(2): p. CD001131.

123. Mathur, S.N., et al., Long-term Intrathecal Baclofen: Outcomes After More than 10 Years of Treatment. PM R, 2013.

124. Ertzgaard, P., C. Campo, and A. Calabrese, Efficacy and safety of oral baclofen in the management of spasticity: A rationale for intrathecal baclofen. J Rehabil Med, 2017. 49(3): p. 193-203.

125. Pucks-Faes, E., et al., Eleven years' experience with Intrathecal Baclofen - Complications, risk factors. Brain Behav, 2018. 8(5): p. e00965.

126. Motta, F. and C.E. Antonello, Analysis of complications in 430 consecutive pediatric patients treated with intrathecal baclofen therapy: 14-year experience. J Neurosurg Pediatr, 2014. 13(3): p. 301-6. 
127. Fjelstad, A.B., J. Hommelstad, and A. Sorteberg, Infections related to intrathecal baclofen therapy in children and adults: frequency and risk factors. J Neurosurg Pediatr, 2009. 4(5): p. 487-93.

128. Turner-Stokes, L. and S. Ashford, Serial injection of botulinum toxin for muscle imbalance due to regional spasticity in the upper limb. Disabil Rehabil, 2007. 29(23): p. 1806-12.

129. Gracies, J.M., et al., Traditional pharmacological treatments for spasticity. Part I: Local treatments. Muscle Nerve Suppl, 1997. 6: p. S61-91.

130. Horn, L.J., G. Singh, and E.R. Dabrowski, Chemoneurolysis with Phenol and Alcohol: $A$ "dying art" that merits revival., in Spasticity: Diagnosis and Management, A. Brashear and E. Elovic, Editors. 2011, Demos Medical Publishing: New York.

131. Ahnert-Hilger, G., A. Münster-Wandowski, and M. Höltje, Synaptic Vesicle Proteins: Targets and Routes for Botulinum Neurotoxins, in Botulinum Neurotoxins. Current Topics in Microbiology and Immunology. Springer: Berlin, Heidelberg.

132. Wissel, J., et al., European consensus table on the use of botulinum toxin type $A$ in adult spasticity. J Rehabil Med, 2009. 41(1): p. 13-25.

133. Gracies, J.M., et al., Efficacy and safety of abobotulinumtoxinA in spastic lower limb: Randomized trial and extension. Neurology, 2017. 89(22): p. 2245-2253.

134. Marciniak, C., et al., Efficacy and Safety of AbobotulinumtoxinA (Dysport) for the Treatment of Hemiparesis in Adults With Upper Limb Spasticity Previously Treated With Botulinum Toxin: Subanalysis From a Phase 3 Randomized Controlled Trial. PM R, 2017. 9(12): p. 11811190.

135. Gupta, A.D., et al., A systematic review: efficacy of botulinum toxin in walking and quality of life in post-stroke lower limb spasticity. Syst Rev, 2018. 7(1): p. 1.

136. Gracies, J.M., et al., Effects of repeated abobotulinumtoxinA injections in upper limb spasticity. Muscle Nerve, 2018. 57(2): p. 245-254.

137. O'Dell, M.W., et al., Dose-Dependent Effects of AbobotulinumtoxinA (Dysport) on Spasticity and Active Movements in Adults With Upper Limb Spasticity: Secondary Analysis of a Phase 3 Study. PM R, 2018. 10(1): p. 1-10.

138. Wissel, J., Towards flexible and tailored botulinum neurotoxin dosing regimens for focal dystonia and spasticity - Insights from recent studies. Toxicon, 2018. 147: p. 100-106.

139. Graham, D., et al., Selective dorsal rhizotomy: current state of practice and the role of imaging. Quant Imaging Med Surg, 2018. 8(2): p. 209-218.

140. Bollens, B., et al., Effects of selective tibial nerve neurotomy as a treatment for adults presenting with spastic equinovarus foot: a systematic review. J Rehabil Med, 2011. 43(4): p. 277-82.

141. Deltombe, T. and T. Gustin, Selective tibial neurotomy in the treatment of spastic equinovarus foot in hemiplegic patients: a 2-year longitudinal follow-up of 30 cases. Arch Phys Med Rehabil, 2010. 91(7): p. 1025-30.

142. Fuller, D.A., Surgery in the Management of Spasticity, in Spasticity: Diagnosis and Management, A. Brashear and E. Elovic, Editors. 2011, Demos Medical Publishing: New York. p. 243-70.

143. Cusick, A., et al., A comparison of goal attainment scaling and the Canadian Occupational Performance Measure for paediatric rehabilitation research. Pediatr Rehabil, 2006. 9(2): p. 149-57.

144. Doig, E., et al., Clinical Utility of the Combined Use of the Canadian Occupational Performance Measure and Goal Attainment Scaling. American Journal of Occupational Therapy, 2010. 64(6): p. 904-914.

145. Ashford, S., et al., Categorisation of goals set using Goal Attainment Scaling for treatment of leg spasticity: a multicentre analysis. Disabil Rehabil, 2018: p. 1-6.

146. Levy, J., et al., Does botulinum toxin treatment improve upper limb active function? Ann Phys Rehabil Med, 2018. 
147. Fleiss, J.L., The design and analysis of clinical experiments. 1986, New York: Wiley-Blackwell. 148. Physicians", R.C.o., et al., Spasticity in adults: management using botulinum toxin. National guidelines 2018. 2018: London.

149. Vikum, E., S. Krokstad, and S. Westin, Socioeconomic inequalities in health care utilisation in Norway: the population-based HUNT3 survey. Int J Equity Health, 2012. 11(48): p. 48.

150. Wastesson, J.W., et al., Inequalities in health care use among older adults in Sweden 19922011: a repeated cross-sectional study of Swedes aged 77 years and older. Scand J Public Health, 2014. 42(8): p. 795-803.

151. Brezzi, M. and P. Luongo, Regional Disparities In Access To Health Care: A Multilevel Analysis In Selected OECD Countries, O.R.D.W. Papers, Editor. 2016, OECD Publishing: Paris.

152. Herwartz, H. and K. Schley, Improving health care service provision by adapting to regional diversity: An efficiency analysis for the case of Germany. Health Policy, 2018. 122(3): p. 293300.

153. Centralbyrån, S., Folkmängd i riket, län och kommuner 31 dec 2014, S. centralbyrån, Editor. 2014.

154. Balakrishnan, S. and A.B. Ward, The diagnosis and management of adults with spasticity. Handb Clin Neurol, 2013. 110: p. 145-60.

155. Ravenni, R., D. De Grandis, and A. Mazza, Conversion ratio between Dysport and Botox in clinical practice: an overview of available evidence. Neurol Sci, 2013. 34(7): p. 1043-8.

156. Regional prislista Landstinget $i$ Uppsala län (Regional price list for Uppsala county council) 2014. [cited 2015 August 4]; Available from: http://svnuppsalaorebro.se/3styrande/prislistor/2014/Uppsala2014-6.pdf.

157. Svensson, J., S. Borg, and P. Nilsson, Costs and quality of life in multiple sclerosis patients with spasticity. Acta Neurol Scand, 2014. 129(1): p. 13-20.

158. Feigin, V.L., et al., Global and regional burden of stroke during 1990-2010: findings from the Global Burden of Disease Study 2010. Lancet, 2014. 383(9913): p. 245-54.

159. Lundstrom, E., A. Terent, and J. Borg, Prevalence of disabling spasticity 1 year after first-ever stroke. Eur J Neurol, 2008. 15(6): p. 533-9.

160. Oreja-Guevara, C., D. Gonzalez-Segura, and C. Vila, Spasticity in multiple sclerosis: results of a patient survey. Int J Neurosci, 2013. 123(6): p. 400-8.

161. Kruse, M., et al., Lifetime costs of cerebral palsy. Dev Med Child Neurol, 2009. 51(8): p. 6228.

162. Andersen, G.L., et al., Cerebral palsy in Norway: prevalence, subtypes and severity. Eur J Paediatr Neurol, 2008. 12(1): p. 4-13.

163. Froslev-Friis, C., et al., Epidemiology of cerebral palsy in Southern Denmark. Dan Med J, 2015. 62(1): p. A4990.

164. National quality register for cerebral palsy in Sweden (CPUP), Annual report. 2013.

165. Dahlberg, A., et al., Prevalence of spinal cord injury in Helsinki. Spinal Cord, 2005. 43(1): p. 47-50.

166. Hagen, E.M., et al., A 50-year follow-up of the incidence of traumatic spinal cord injuries in Western Norway. Spinal Cord, 2010. 48(4): p. 313-8.

167. Barnes, M.P., Rehabilitation after traumatic brain injury. Br Med Bull, 1999. 55(4): p. 927-43.

168. Singer, B.J., et al., Incidence of ankle contracture after moderate to severe acquired brain injury. Arch Phys Med Rehabil, 2004. 85(9): p. 1465-9.

169. Radensky, P.W., et al., The Estimated Cost of Managing Focal Spasticity: A Physician Practice Patterns Survey. Neurorehabilitation and Neural Repair, 2001. 15(1): p. 57-68.

170. Ward, A., et al., Cost-effectiveness of botulinum toxin type $a$ in the treatment of post-stroke spasticity. J Rehabil Med, 2005. 37(4): p. 252-7.

171. Ng, S.S. and C.W. Hui-Chan, Transcutaneous electrical nerve stimulation combined with taskrelated training improves lower limb functions in subjects with chronic stroke. Stroke, 2007. 38(11): p. 2953-9. 
172. Ng, S.S. and C.W. Hui-Chan, Does the use of TENS increase the effectiveness of exercise for improving walking after stroke? A randomized controlled clinical trial. Clin Rehabil, 2009. 23(12): p. 1093-103.

173. Yan, T. and C.W. Hui-Chan, Transcutaneous electrical stimulation on acupuncture points improves muscle function in subjects after acute stroke: a randomized controlled trial. J Rehabil Med, 2009. 41(5): p. 312-6.

174. Yan, T., C.W. Hui-Chan, and L.S. Li, Functional electrical stimulation improves motor recovery of the lower extremity and walking ability of subjects with first acute stroke: a randomized placebo-controlled trial. Stroke, 2005. 36(1): p. 80-5.

175. Ping Ho Chung, B. and B. Kam Kwan Cheng, Immediate effect of transcutaneous electrical nerve stimulation on spasticity in patients with spinal cord injury. Clin Rehabil, 2010. 24(3): p. 202-10.

176. Tekeoglu, Y., B. Adak, and T. Goksoy, Effect of transcutaneous electrical nerve stimulation (TENS) on Barthel Activities of Daily Living (ADL) index score following stroke. Clin Rehabil, 1998. 12(4): p. 277-80.

177. Cheng, J.S., et al., Effects of combining electric stimulation with active ankle dorsiflexion while standing on a rocker board: a pilot study for subjects with spastic foot after stroke. Arch Phys Med Rehabil, 2010. 91(4): p. 505-12.

178. Kwong, P.W., et al., Transcutaneous electrical nerve stimulation improves walking capacity and reduces spasticity in stroke survivors: a systematic review and meta-analysis. Clin Rehabil, 2018. 32(9): p. 1203-1219.

179. Priebe, M.M., et al., Clinical assessment of spasticity in spinal cord injury: a multidimensional problem. Arch Phys Med Rehabil, 1996. 77(7): p. 713-6.

180. Lyle, R.C., A performance test for assessment of upper limb function in physical rehabilitation treatment and research. Int J Rehabil Res, 1981. 4(4): p. 483-92.

181. Van der Lee, J.H., et al., The intra- and interrater reliability of the action research arm test: $a$ practical test of upper extremity function in patients with stroke. Arch Phys Med Rehabil, 2001. 82(1): p. 14-9.

182. Hodics, T.M., et al., Wolf Motor Function Test for characterizing moderate to severe hemiparesis in stroke patients. Arch Phys Med Rehabil, 2012. 93(11): p. 1963-7.

183. Evans, M.D., P.A. Goldie, and K.D. Hill, Systematic and random error in repeated measurements of temporal and distance parameters of gait after stroke. Arch Phys Med Rehabil, 1997. 78(7): p. 725-9.

184. Dean, C.M., C.L. Richards, and F. Malouin, Task-related circuit training improves performance of locomotor tasks in chronic stroke: a randomized, controlled pilot trial. Arch Phys Med Rehabil, 2000. 81(4): p. 409-17.

185. Hutin, E., et al., Intra- and inter-rater reliability of the 10-meter ambulation test in hemiparesis is better barefoot at maximal speed. Top Stroke Rehabil, 2018: p. 1-6.

186. Sullivan, M., J. Karlsson, and J.E. Ware, Jr., The Swedish SF-36 Health Survey--I. Evaluation of data quality, scaling assumptions, reliability and construct validity across general populations in Sweden. Soc Sci Med, 1995. 41(10): p. 1349-58.

187. Whynes, D.K. and T. Group, Correspondence between EQ-5D health state classifications and EQ VAS scores. Health Qual Life Outcomes, 2008. 6: p. 94.

188. Krevers, B., A.L. Narvanen, and B. Oberg, Patient evaluation of the care and rehabilitation process in geriatric hospital care. Disabil Rehabil, 2002. 24(9): p. 482-91.

189. Alwin, J., J. Persson, and B. Krevers, Perception and significance of an assistive technology intervention - the perspectives of relatives of persons with dementia. Disabil Rehabil, 2013. 35(18): p. 1519-26.

190. Sandsjö, L., et al., Participants' views on the "blinding" aspect of a RCT study Experiences from evaluation of a TES concept for self-administered treatment of spasticity, in ISEK 2018 - 
The XXII Congress of the International Society of Electrophysiology and Kinesiology. 2018, University College Dublin Press: Univeristy College Dublin, Dublin, Ireland.

191. Alabdulwahab, S.S. and M. Al-Gabbani, Transcutaneous electrical nerve stimulation of hip adductors improves gait parameters of children with spastic diplegic cerebral palsy. NeuroRehabilitation, 2010. 26(2): p. 115-22.

192. Veltink, P.H., M. Ladouceur, and T. Sinkjær, Inhibition of the triceps surae stretch reflex by stimulation of the deep peroneal nerve in persons with spastic stroke. Archives of Physical Medicine and Rehabilitation, 2000. 81(8): p. 1016-1024.

193. Koyama, S., et al., Modulation of spinal inhibitory reflexes depends on the frequency of transcutaneous electrical nerve stimulation in spastic stroke survivors. Somatosens Mot Res, 2016: p. 1-8.

194. Ploughman, M., et al., The effects of poststroke aerobic exercise on neuroplasticity: $a$ systematic review of animal and clinical studies. Transl Stroke Res, 2015. 6(1): p. 13-28.

195. Wang, R., J. Gaverth, and P.A. Herman, Changes in the Neural and Non-neural Related Properties of the Spastic Wrist Flexors After Treatment With Botulinum Toxin A in Post-stroke Subjects: An Optimization Study. Front Bioeng Biotechnol, 2018. 6: p. 73. 


\section{APPENDIX 1}

The included tables on instruments used in spasticity research are published at the courtesy of the Ability Network. The data were collected as part of the development of a clinical pathway including recommendations on evaluation tools for spasticity in SCI $[6,60,99]$. The instruments related to SCI is published [60].

\section{Methods}

This was a targeted literature review searching the MedLine, Embase and Cochrane databases from 1995 to 2015. Searches were run on 17 May 2015.

\section{Search strategy and hits}

The search strategy was:

Spasticity AND (impairment OR function OR functioning) AND (assessment OR measurement OR evaluation)

- Clinical trial and review (for Pubmed)

- Article and article in press (for Embase)

- Human

Only journal articles were included; conference abstracts were not included. This resulted in the following numbers of hits:

- Pubmed (with Medline) 01.01.1995-17.05.2015: 1494 publications

- Embase (without Medline) 1995-2015: 236 publications

- Cochrane Database of Systematic Reviews: 124 publications

- Cochrane Central Register of Controlled Trials: 219 publications

\section{Inclusion criteria}

- Studies were included if they involved $\geq 10$ patients and reported clinical or functional outcome measures in patients with spasticity.

\section{Exclusion criteria}

- Studies whose sole purpose was to research the measures themselves (e.g. inter-rater reliability studies, studies of relationships between measures and laboratory findings).

- Studies that only had physiological, laboratory or electrophysiological evaluations, i.e. where there was no clinical or functional assessment. However, the use of electrophysiological and mechanical evaluations was noted where these were part of included studies.

- Studies whose only outcome measure was goal attainment, unless goal attainment was measured using the Goal Attainment Scale (i.e. we did not include informal measures of goal attainment).

After screening and deduplication, 426 studies were included. 


\section{Data extraction and limitations}

We extracted details of patient population and measures used in each study, and the number of studies, using each measure, was tabulated by indication. Because of the very large number of included studies, outcome measures were extracted from the abstracts when possible. We found that the majority of abstracts listed the primary and secondary outcome measures of the study. Where the abstract did not contain this information, or we suspected that the list was incomplete, the full paper was reviewed.

Some relevant outcome measures may have been missed if they were included in the full paper but not mentioned in the list of outcomes in the abstract; however, we believe this would be infrequent, because most papers appeared to give a comprehensive list of outcome measures in the abstract. Therefore, we do not believe that it is a major limitation to the review.

Ashworth/modified Ashworth, Tardieu and Barthel Index scales: mentions of the modified and original versions of these measures were extracted separately. However, it is possible that some authors used the modified scale but failed to specify 'modified' in the abstract. In order to meaningfully compare the frequency of use of the two forms of any of these scales, it would be necessary to obtain the full papers for all the studies where 'Ashworth Scale', 'Tardieu Scale' or 'Barthel Index' was specified, to verify which form was used.

\section{The following measures occurring in less than three studies were not included in the tabulation:}

Abbott Scale, ABILOCO/ABILOCO kids, Ability to transfer, Achilles tendon reflex test, Ambulation Index, American Spinal Injury Association Impairment Scale, Anglo Dutch Spasticity Measurement Tool, Bimanual Fine Motor Function, Brace Wear Scale, Brief Pain Inventory, Bruinsky-Oseretsky Test of Motor Proficiency, Burden of Stroke Scale, Disabilities of Arm Shoulder and Hand Score, Disability Rating Scale, Disability self-reported rating, Duncan Ely Test, Emory Functional Ambulation Profile, Functional Assessment Measure, Functional Assessment Scale, Functional Disability Score, Functional Reach Test, Gait Profile Score, Global Assessment of Spasticity Scale, Gross Motor Performance Measure, Guy's Neurological Disability Scale, Held's score, House Scale, Illinois St Louis Scale, Incapacity Status Scale, Index of Muscle Function, ITB Survey, International Standard for Neurological Classification of SCI, Jikei Assessment Scale for Motor Impairment, Kocaeli Functional Assessment Scale, Manual Ability Classification, McGill Pain Questionnaire, Multiple Sclerosis Impact Scale, Multiple Sclerosis Impairment Scale, Multiple Sclerosis Walking Scale, New Functional Ambulatory Classification, Patient Disability Scale, Pediatric Balance Scale, Pediatric Disability Scale, Pediatric Outcomes Data Collection Instrument, Postural Assessment Scale for Stroke Patients, Questionnaire on Pain Caused by Spasticity, Rating of Response to BtxA, REPAS Spasticity Scale, Santa Casa Evaluation of Spasticity Scale, Selective Control Assessment of Lower Extremity, Simple Test for Evaluation Hand Function, Spinal Cord Independence Measure (SCIM), Stroke Impact Scale, Stroke Rehabilitation Assessment of Movement, Thomas Test, Tone Assessment Scale, Toulouse Motor Scale, Triple Spasticity Scale, Upper Extremity Utility Score and Walking tests (other timed or distance). 
Table 1: Measures used for Body function and structures in spasticity research

\begin{tabular}{|c|c|c|c|c|c|c|c|c|}
\hline \multirow{2}{*}{$\begin{array}{l}\text { Measure } \\
\text { Body function and } \\
\text { structure }\end{array}$} & \multicolumn{7}{|c|}{ Indication (Number of studies, $n$ ) } & \multirow{2}{*}{$\begin{array}{r}\text { Total } \\
n=424\end{array}$} \\
\hline & $\begin{array}{c}\mathbf{A L S} \\
\mathrm{n}=2\end{array}$ & $\begin{array}{c}\mathbf{C P} \\
\mathrm{n}=132\end{array}$ & $\begin{array}{c}\text { MS } \\
\mathrm{n}=19\end{array}$ & $\begin{array}{c}\text { SCI } \\
\mathrm{n}=26\end{array}$ & $\begin{array}{c}\text { Stroke } \\
\mathrm{n}=171\end{array}$ & $\begin{array}{l}\text { TBI/ } \\
\text { ABI } \\
n=6^{b}\end{array}$ & $\begin{array}{l}\text { Mixed/NR } \\
\text { /Otherc } \\
n=68^{\mathrm{a}} \\
\end{array}$ & \\
\hline Ashworth Scale & - & 16 & 5 & 10 & 33 & 3 & 23 & 90 \\
\hline $\begin{array}{l}\text { Ashworth Scale, } \\
\text { Modified }\end{array}$ & 2 & 57 & 13 & 2 & 98 & 9 & 27 & 208 \\
\hline $\begin{array}{l}\text { Brunnström Motor } \\
\text { Recovery }\end{array}$ & - & - & - & - & 13 & - & - & 13 \\
\hline Clonus Score & - & - & 1 & 2 & 2 & - & - & 5 \\
\hline $\begin{array}{l}\text { Composite Spasticity } \\
\text { Scale }\end{array}$ & - & 1 & - & - & 4 & - & - & 5 \\
\hline $\begin{array}{l}\text { Electrophysiological } \\
\text { evaluations }\end{array}$ & - & 7 & 2 & 9 & 22 & - & 7 & 44 \\
\hline Fugl-Meyer Assessment & - & - & - & - & 63 & - & 5 & 69 \\
\hline Gait Deviation Index & - & 3 & - & - & - & - & - & 3 \\
\hline $\begin{array}{l}\text { Lindmark Motor } \\
\text { Assessment Scale }\end{array}$ & - & - & 1 & - & 2 & - & - & 3 \\
\hline Manual Muscle Test & - & 2 & 1 & - & 4 & - & - & 7 \\
\hline Mechanical evaluations & - & 14 & 1 & 4 & 14 & 1 & 7 & 41 \\
\hline Modified Tardieu Scale & - & 8 & - & - & - & - & 2 & 10 \\
\hline Motricity Index & - & - & - & - & 4 & - & - & 4 \\
\hline $\begin{array}{l}\text { MRC (Medical Research } \\
\text { Council) Scale }\end{array}$ & - & 1 & - & - & 7 & - & 2 & 10 \\
\hline NIH Stroke Scale & - & - & - & - & 3 & - & - & 3 \\
\hline $\begin{array}{l}\text { Numeric Pain Rating } \\
\text { Scale }\end{array}$ & 1 & 1 & 2 & 1 & 2 & - & 1 & 8 \\
\hline $\begin{array}{l}\text { Range of } \\
\text { motion/goniometry }\end{array}$ & - & 49 & - & 2 & 54 & 3 & 19 & 128 \\
\hline $\begin{array}{l}\text { Spasm Frequency } \\
\text { Scale(Penn) }\end{array}$ & 2 & 1 & 1 & 8 & 3 & 1 & 5 & 21 \\
\hline $\begin{array}{l}\text { Spinal Cord Assessment } \\
\text { Tool Spastic Reflexes } \\
\text { (SCATS) }\end{array}$ & - & - & - & 4 & - & - & - & 4 \\
\hline Tardieu Scale & - & 3 & - & - & 3 & 1 & 2 & 9 \\
\hline VAS, Pain & - & - & 2 & - & 9 & - & 8 & 19 \\
\hline VAS, Other ${ }^{d}$ & - & 3 & 1 & 5 & 3 & 1 & 5 & 18 \\
\hline $\begin{array}{l}\text { Wartenburg Pendulum/ } \\
\text { Pendulum Test }\end{array}$ & - & 1 & - & 2 & - & - & - & 3 \\
\hline Zancolli Classification & - & 1 & - & - & - & 1 & 1 & 3 \\
\hline
\end{tabular}

Abbreviations: ALS, Amyotrophic lateral sclerosis; CP, Cerebral palsy; MS, Multiple sclerosis; N, Number of studies; NR, Not reported; SCI, Spinal cord injury; TBI/ABI, Traumatic brain injury/Acquired brain injury; VAS, Visual analogue scale Footnotes: a) 37 Mixed, 25 Not reported, 6 Other; b) 2 ABI, 4 TBI; c) SPOAN (spastic paraplegia, optic atrophy, and neuropathy); Hereditary spastic paraplegia; Chronic hemiplegia d) Other VAS: spasticity, gait, function, goal attainment, degree of benefit, not specified ; e) Total number of studies utilizing modified and unmodified versions of the same measure were combined to assess frequency of use relative to other measures. 
Table 2: Measures used for activity and participation in spasticity research

\begin{tabular}{|c|c|c|c|c|c|c|c|c|}
\hline \multirow{2}{*}{$\begin{array}{l}\text { Measure } \\
\text { Activity and } \\
\text { Participation }\end{array}$} & \multicolumn{7}{|c|}{ Indication (Number of studies, $\mathbf{n}$ ) } & \multirow{2}{*}{$\begin{array}{c}\text { Total } \\
\mathbf{n}=\mathbf{4 2 4} *\end{array}$} \\
\hline & $\begin{array}{c}\text { ALS } \\
\mathrm{n}=2\end{array}$ & $\underset{\mathrm{n}=132}{\mathbf{C P}}$ & $\underset{\mathrm{n}=19}{\mathbf{M S}}$ & $\underset{\mathrm{n}=26}{\mathbf{S C I}}$ & $\begin{array}{l}\text { Stroke } \\
\mathrm{n}=171\end{array}$ & $\begin{array}{l}\text { TBI/ } \\
\text { ABI } \\
\mathrm{n}=6^{\mathrm{b}}\end{array}$ & $\begin{array}{c}\text { Mixed/NR } \\
\text { /Other } \\
\text { n=68 }\end{array}$ & \\
\hline Abilhand/Abilhand kids & - & 5 & - & - & - & - & - & 5 \\
\hline $\begin{array}{l}\text { Action Research Arm } \\
\text { Test }\end{array}$ & - & - & - & - & 10 & 1 & 3 & 14 \\
\hline $\begin{array}{l}\text { Assisting Hand } \\
\text { Assessment }\end{array}$ & - & 5 & - & - & - & - & 1 & 6 \\
\hline $\begin{array}{l}\text { Barthel/Modified Barthel } \\
\text { Index }\end{array}$ & - & - & 2 & - & 29 & - & 4 & 35 \\
\hline Berg Balance Scale & - & 2 & 3 & 1 & 6 & - & 1 & 13 \\
\hline Box and Block test & - & 2 & - & - & 6 & 1 & 2 & 11 \\
\hline $\begin{array}{l}\text { Disability Assessment } \\
\text { Scale (DAS) }\end{array}$ & - & - & - & - & 6 & - & 1 & 7 \\
\hline $\begin{array}{l}\text { Expanded Disability } \\
\text { Status Scale (EDSS) }\end{array}$ & - & - & 4 & - & 1 & - & 1 & 6 \\
\hline $\begin{array}{l}\text { Frenchay/Modified } \\
\text { Frenchay Arm Test }\end{array}$ & - & - & - & - & 2 & - & 1 & 3 \\
\hline $\begin{array}{l}\text { Functional Ambulation } \\
\text { Category (FAC) }\end{array}$ & - & - & - & - & 5 & - & 3 & 8 \\
\hline $\begin{array}{l}\text { Functional Independence } \\
\text { Measure (FIM) }\end{array}$ & - & 2 & - & 5 & 18 & - & 4 & 29 \\
\hline $\begin{array}{l}\text { Functional Independence } \\
\text { Measure, Wee (WeeFIM) }\end{array}$ & - & 4 & - & - & - & - & 1 & 5 \\
\hline Functional Mobility Scale & - & 4 & - & - & - & - & 1 & 5 \\
\hline Gait analysis & - & 24 & - & - & 14 & - & 9 & 44 \\
\hline $\begin{array}{l}\text { Gillette Functional } \\
\text { Assessment }\end{array}$ & - & 4 & - & - & - & - & 1 & 5 \\
\hline Gillette Gait Index & - & 4 & - & - & - & - & - & 4 \\
\hline $\begin{array}{l}\text { Gross Motor Function } \\
\text { Classification System } \\
\text { (GMFCS) }\end{array}$ & - & 14 & - & - & - & - & - & 14 \\
\hline $\begin{array}{l}\text { Gross Motor Function } \\
\text { Measure (GMFM) }\end{array}$ & - & 60 & - & - & - & - & 3 & 63 \\
\hline $\begin{array}{l}\text { Jebsen Hand Function } \\
\text { Test }\end{array}$ & - & 4 & - & - & 3 & - & - & 7 \\
\hline $\begin{array}{l}\text { Lindmark Motor } \\
\text { Assessment Scale }\end{array}$ & - & - & 1 & - & 2 & - & - & 3 \\
\hline $\begin{array}{l}\text { Melbourne Assessment } \\
\text { Unilateral Upper Limb } \\
\text { Function }\end{array}$ & - & 4 & - & - & - & - & - & 4 \\
\hline $\begin{array}{l}\text { Modified/Motor } \\
\text { Assessment Scale } \\
\text { (M/MAS) }\end{array}$ & - & - & - & - & 6 & - & - & 6 \\
\hline Modified Rankin Scale & - & - & - & - & 4 & - & - & 4 \\
\hline Nine-hole Peg Test & - & 1 & 1 & - & 3 & 1 & - & 6 \\
\hline $\begin{array}{l}\text { Paediatric Evaluation } \\
\text { Disability Inventory } \\
\text { (PEDI) }\end{array}$ & - & 19 & - & - & - & - & 2 & 21 \\
\hline $\begin{array}{l}\text { Physician Global } \\
\text { Rating/Rating } \\
\text { Scale/Impression of } \\
\text { Change }\end{array}$ & - & 13 & 1 & 2 & 7 & - & 1 & 24 \\
\hline
\end{tabular}




\begin{tabular}{|c|c|c|c|c|c|c|c|c|}
\hline Quality of Upper & & & & & & & & \\
\hline $\begin{array}{l}\text { Extremity Skills Test } \\
\text { (QUEST) }\end{array}$ & - & 6 & - & - & - & - & - & 6 \\
\hline $\begin{array}{l}\text { Rivermead Motor } \\
\text { Assessment/Mobility } \\
\text { Index }\end{array}$ & - & - & - & - & 13 & - & 3 & 16 \\
\hline $\begin{array}{l}\text { Selective Motor Control } \\
\text { Scale }\end{array}$ & - & 6 & - & - & - & - & - & 6 \\
\hline 6 min Walk Test & - & 7 & 1 & 2 & 6 & - & 1 & 17 \\
\hline $\begin{array}{l}\text { Stroke Impairment } \\
\text { Assessment Set }\end{array}$ & - & - & - & - & 5 & - & - & 5 \\
\hline $10 \mathrm{~m}$ Walk Test & - & 3 & 6 & 3 & 12 & - & 3 & 27 \\
\hline Timed Up and Go & - & 5 & 3 & 3 & 7 & - & 1 & 19 \\
\hline $\begin{array}{l}\text { Upper Extremity } \\
\text { Function Test }\end{array}$ & - & - & - & - & 2 & - & 1 & 3 \\
\hline $\begin{array}{l}\text { Walking Index for SCI } \\
\text { (WISCI, WISCI II) }\end{array}$ & - & - & - & 3 & - & - & - & 3 \\
\hline $\begin{array}{l}\text { Wolf Motor Function } \\
\text { Test }\end{array}$ & - & - & - & - & 15 & - & - & 15 \\
\hline
\end{tabular}

Table 3: Measures used for PROs as HRQoL measures in spasticity research

\begin{tabular}{|c|c|c|c|c|c|c|c|c|}
\hline \multirow{2}{*}{$\begin{array}{l}\text { Measure } \\
\text { PROM's * }\end{array}$} & \multicolumn{7}{|c|}{$\begin{array}{c}\text { Indication } \\
\text { (Number of studies, } n \text { ) }\end{array}$} & \multirow{2}{*}{$\begin{array}{c}\text { Total } \\
\mathrm{n}=424^{*}\end{array}$} \\
\hline & $\begin{array}{c}\mathbf{A L S} \\
\mathrm{n}=2\end{array}$ & $\begin{array}{c}\mathbf{C P} \\
\mathrm{n}=132\end{array}$ & $\begin{array}{c}\text { MS } \\
\mathrm{n}=19\end{array}$ & $\begin{array}{c}\text { SCI } \\
\mathrm{n}=26\end{array}$ & $\begin{array}{c}\text { Stroke } \\
\mathrm{n}=171\end{array}$ & $\begin{array}{l}\text { TBI/ } \\
\text { ABI } \\
n=6^{b}\end{array}$ & $\begin{array}{c}\text { Mixed/NR } \\
\text { /Other }^{\mathrm{c}} \\
\mathrm{n}=68^{\mathrm{a}}\end{array}$ & \\
\hline $\begin{array}{l}\text { Canadian Occupational } \\
\text { Performance Measure } \\
\text { (COPM) }\end{array}$ & - & 6 & - & - & 2 & - & 2 & 10 \\
\hline $\begin{array}{l}\text { Goal Attainment Scale } \\
\text { (GAS) }\end{array}$ & - & 8 & - & - & 5 & 1 & 5 & 19 \\
\hline $\begin{array}{l}\text { Multiple Sclerosis } \\
\text { Spasticity Scale }\end{array}$ & - & - & 3 & - & - & - & - & 3 \\
\hline $\begin{array}{l}\text { Patient Reported Impact } \\
\text { of Spasticity Measure } \\
\text { (PRISM) }\end{array}$ & - & - & - & 2 & - & - & - & 2 \\
\hline $\begin{array}{l}\text { Spinal Cord Injury } \\
\text { Spasticity Evaluation } \\
\text { Tool (SCI-SET) }\end{array}$ & - & - & - & 3 & - & - & - & 3 \\
\hline $\begin{array}{l}\text { Abbreviations: ALS, Amy } \\
\text { Number of studies; NR, N } \\
\text { injury/Acquired brain inju } \\
\text { Footnotes: a) } 37 \text { Mixed, } 2 \\
\text { optic atrophy, and neuropa } \\
\text { spasticity, gait, function, } \\
\text { utilizing modified and unn } \\
\text { of use relative to other me }\end{array}$ & $\begin{array}{l}\text { rophic } \\
\text { report } \\
\text {; VAS, } \\
\text { Not rep } \\
\text { hy); He } \\
\text { al attain } \\
\text { dified } \\
\text { ures. }\end{array}$ & $\begin{array}{l}\text { ateral sc } \\
\text { d; SCI, } \\
\text { Visual a } \\
\text { rted, } 6 \text { ( } \\
\text { editary s } \\
\text { ment, de } \\
\text { ersions }\end{array}$ & $\begin{array}{l}\text { erosis; } \\
\text { oinal co } \\
\text { alogue } \\
\text { ther; b) } \\
\text { astic pe } \\
\text { ree of b } \\
\text { f the sa }\end{array}$ & $\begin{array}{l}\text { P, Cere } \\
\text { d injur } \\
\text { cale } \\
\text { ABI, } \\
\text { aplegic } \\
\text { nefit, } \\
\text { e meas }\end{array}$ & $\begin{array}{l}\text { TBal palsy } \\
\text { TBI; c) } \\
\text { Chronic } \\
\text { t specifi } \\
\text { ire were }\end{array}$ & $\begin{array}{l}\text { MS, } \\
\text { [, Trau } \\
\text { POAN } \\
\text { hemipl } \\
\text { d ; e) } \\
\text { ombin }\end{array}$ & $\begin{array}{l}\text { ultiple scler } \\
\text { latic brain } \\
\text { (spastic para } \\
\text { gia d) Other } \\
\text { tal number } \\
\text { to assess fr }\end{array}$ & $\begin{array}{l}\text { is; } \mathrm{N} \text {, } \\
\text { legia, } \\
\text { AS: } \\
\text { f studies } \\
\text { quency }\end{array}$ \\
\hline
\end{tabular}





\section{Papers}

The papers associated with this thesis have been removed for copyright reasons. For more details about these see:

http://urn.kb.se/resolve?urn=urn:nbn:se:liu:diva-152853 